\title{
Murine models to investigate the influence of diabetic metabolism on the development of atherosclerosis and restenosis
}

\section{Herminia Gonzalez-Navarro ${ }^{1}$, Deborah J. Burks ${ }^{2}$ and Vicente Andres ${ }^{1}$}

${ }^{1}$ Laboratory of Vascular Biology, Department of Molecular and Cellular Pathology and Therapy, Instituto de Biomedicina de Valencia (IBV-CSIC), Valencia, Spain, ${ }^{2}$ Centro de Investigacion Principe Felipe, Department of Molecular Endocrinology, Valencia, Spain

\section{TABLE OF CONTENTS}

1. Abstract

2. Diabetes and atherosclerosis

3. Mouse models of Type 1-Diabetes combined with atherosclerosis

3.1. Streptozotocin treatment

3.2. The GP transgenic:LDLR-KO mouse

3.3. The non-obese diabetic (NOD) mouse

4. Mouse models of Type 2-Diabetes combined with atherosclerosis

4.1. Diabetogenic diets to induce atherosclerosis in susceptible mouse strains

4.2. Lipocalin-type prostaglandin $\mathrm{D}(2)$ synthase (L-PGDS)-deficient mice

4.3. Gold thioglucose (GTG)-induced obesity-related type 2-diabetes in the apoE-KO mouse model

4.4. Leptin receptor-deficient $\left(\operatorname{Lepr}^{\mathrm{db} / \mathrm{db}}\right)$ and leptin-deficient $\left(\mathrm{Lep}^{\mathrm{ob} / \mathrm{ob}}\right)$ mouse models

4.5. Defective insulin signaling and atherosclerosis: Insulin receptor and insulin receptor substrate 2-null mice

5. Animal models to study the effects of altered leptin/glucose/insulin signaling on neointimal thickening induced by mechanical injury of the vessel wall

5.1. Type 1-diabetes models

5.2. Lepr $^{\mathrm{db} / \mathrm{db}}$ mice

5.3. IRS-deficient mice

5.4. Role of hyperinsulinemia

6. Experimental therapies for treating diabetic atherosclerosis

6.1. Inhibition of the AGE pathway

6.2. Blockade of the renin-angiotensin system

6.3. Imatinib

6.4. 17ß-estradiol

6.5. Inhibition of $11 \beta$-hydroxysteroid dehydrogenase type 1 (11 -HSD1) activity

6.6. The thromboxane A2 receptor antagonist S18886

6.7. Peroxisome proliferator-activated receptor (PPAR) agonists

6.8. Antioxidant therapy: polyphenols, $\alpha$-lipoic acid and paraoxonase 1 (PON 1)

7. Conclusions and future perspectives

8. Acknowledgements

9. References

\section{ABSTRACT}

Atherosclerosis and related forms of cardiovascular disease (CVD) are associated with several genetic and environmental risk factors, including hypercholesterolemia, diabetes mellitus (DM), hypertension, obesity and smoking. Human DM is a multisystem disorder that results from progressive failure of insulin production and insulin resistance. Most diabetic patients die from complications of atherosclerosis and CVD, and DM is also associated with increased risk of restenosis post-angioplasty. Furthermore, the incidence of DM, particularly type 2-DM, is expected to increase significantly during the next decades owing to the unhealthy effects of modern life-style habits (e.g., obesity and lack of physical exercise). Thus, it is of utmost importance to develop novel preventive and therapeutic strategies to reduce the social and health-care burden of CVD and DM. Although a number of physiological alterations thought to promote atherosclerosis have been identified in diabetic patients, the precise molecular mechanisms that link DM and atherosclerosis are largely unknown. Thus, the aim of this review is to discuss current murine models of combined DM and atherosclerosis and to explore how these experimental systems are being utilized to gain mechanistic insights into diabetes-induced neointimal lesion development, as well as their potential use in evaluating the efficacy 
of new therapies. Our discussion includes models generated by streptozotocin treatment and those resulting from naturally occurring or targeted mutations in the mouse.

\section{DIABETES AND ATHEROSCLEROSIS}

Despite major efforts during the last decades to identify cardiovascular risk factors (CRFs) and to elucidate the cellular and molecular mechanisms involved in the initiation and progression of the atherosclerotic plaque, atherosclerosis and associated CVD are the major cause of mortality and morbidity in Western societies, and their incidence in developing countries is increasing at alarming rates (1). Experimental and clinical studies have revealed that atherosclerosis is a chronic inflammatory disease resulting from the interaction between atherogenic stimuli and elements of the arterial wall $(1,2)$. Native and adaptative immune mechanisms seem to play major roles in the aetiology and pathogenesis of atherosclerosis $(3,4)$. The inflammatory process leads to the development of complex lesions and rupture of atherosclerotic plaques at advanced disease states provokes thrombus formation and acute clinical complications (i. e. stroke and myocardial infarction).

In addition to predisposing genetic factors, a number of modifiable CRFs are known to promote the development of atherosclerosis and CVD, including hyperlipidemia, hypertension, obesity, smoking, and DM $(1,2,4-6)$. There is a wealth of clinical data demonstrating a relationship between the two major forms of DM (type 1 or insulin-dependent, and type 2 or noninsulin-dependent) and atherosclerosis and its clinical complications, with diabetic patients exhibiting a 2 to 10 -fold higher risk of macrovascular disease than the general population (7-10) (see also http://www.who.int/diabetes/en). DM affects approximately 100 million persons worldwide, with $90-95 \%$ patients suffering from type 2 -DM, $80 \%$ of which die from complications of atherosclerosis (7-10). DM is often linked to the pathophysiology known as the metabolic syndrome, which combines glucose intolerance, hyperlipidemia, obesity, and hypertension (11). This coalescence of unfavorable health factors affects approximately one quarter of the population in industrialized countries and is associated with a marked increase in the risk of CVD. Remarkably, the incidence of type 2-DM is expected to increase by $165 \%$ between 2000 and 2050 (11), representing the plague of the $21^{\mathrm{st}}$ century, caused by increases of obesity and aging in the population (12). It is now estimated that the metabolic syndrome has a greater detrimental effect on our overall health as a society than cancer. Therefore, there is an enormous need for therapeutic and preventive measures to control this epidemic of metabolic diseases $(13,14)$.

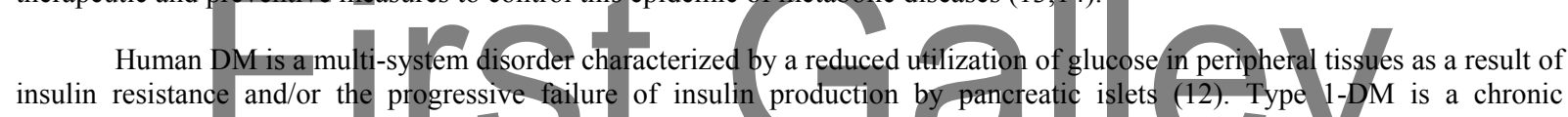
autoimmune disease triggered by the autoimmune destruction of panereatic insulin-producing $\beta$-cells (15). Human type 1-DM is frequently associated with polymorphisms in HLA class II, although environmental factors such as pathogens, toxins, drugs and especially viruses have been implicated (15-18). To some extent, it is possible to identify individuals at high risk for type 1-DM because circulating auto-antibodies are present years before the onset of clinical symptoms. By contrast, type 2-DM occurs when the pancreas fails to produce sufficient insulin to cope with an increasing metabolic demand; this may reflect an acquired defect of insulin secretion or synthesis and/or a decrease in $\beta$-cell mass (19). In adult humans, $\beta$-cell mass is plastic and the balance between insulin supply and metabolic demand is maintained by adjustments to $\beta$-cell growth and survival. However, eventually this $\beta$-cell adaptation fails since type 2-DM patients show a decrease in the $\beta$-cell mass. Type 2-DM is a condition that usually co-exists with the metabolic syndrome which is characterized by abdominal obesity, hyperglycemia, hyperinsulinemia, insulin resistance, hypertension, dyslipidemia, and microalbuminuria $(11,20,21-23)$. Recently, dyslipidemia has also been found in a subset of patients with type 1-DM that have elevated intra-abdominal fat accumulation and obesity (24). Pro-atherogenic lipid alterations in the plasma of DM patients that are expected to accelerate atherosclerosis include: (1) increased triglyceride (TG) and free fatty acid (FFA) levels, (2) decreased content of cholesterol bound to high-density lipoproteins (HDL-cholesterol), and (3) the presence of the pro-atherogenic small dense low-density lipoproteins (sdLDLs), which has been used as a marker for the metabolic syndrome and type 2-DM $(20,21,22,25)$. These alterations are hypothesized to produce endothelial dysfunction, which triggers atherosclerosis and CVD (26).

DM provokes other vascular complications that accelerate atherosclerosis and involve different cell types in the arterial wall, such as endothelial cells (ECs), vascular smooth muscle cells (VSMCs) and platelets (8-11,27). DM triggers EC dysfunction by impairing endothelium-dependent (nitric oxide-mediated) vasodilatation $(8,28)$. Hyperglycemia inhibits the production of nitric oxide (NO) by blocking endothelial NO synthase (eNOS) activation, and also increases the production of reactive oxygen species (ROS) in ECs and VSMCs, which in turn activate receptors for advanced glycation end-products (RAGE). Lipid abnormalities in DM, like increased very low-density lipoprotein (VLDL) and FFA plasmatic levels, can promote growth of atherosclerotic lesions by inducing transcription factors involved in the expression of proatherogenic molecules (i. e. adhesion molecules, chemokines and other proinflammatory mediators). When nascent fatty streaks form, VSMCs migrate into the intimal lesion and stabilize the atheroma by producing collagen. Diabetic ECs display increased production of cytokines that lower in VSMCs the production of collagen an additional extracellular matrix component that confer plaque stability. Moreover, DM increases the production of metalloproteinases that lead to breakdown of collagen. Thus, the combination of reduced collagen synthesis and increased collagen breakdown predisposes diabetics to plaque rupture and higher risk of thrombus formation (8). 
Hyperglycemia may also facilitate plaque instability and rupture through direct actions on VSMCs. Glycated LDLs activate VSMC migration; however, oxidized glycated LDLs can induce VSMC apoptosis thus reducing collagen content within the lesion $(8,29)$. Hyperglycemia also enhances thrombogenesis by activating platelets and reducing production of endogenous platelet inhibitors. Moreover, DM patients display an increase in blood clotting due to impaired fibrinolytic activity, increased levels of procoagulants (i. e. tissue factor) and coagulants (i. e. factor VII), and decreased endogenous anticoagulant levels (such as antithrombin III and protein C). In summary, DM promotes atherosclerotic lesion formation, increases plaque instability, and favors the formation and persistence of thrombi $(8,29)$.

The next sections discuss current mouse models which have been used to investigate the relationship between DM and atherosclerosis/restenosis, including naturally occurring mouse mutants and genetically-engineered mice with phenotypes similar to human DM (Table 3 and 4). Because the mouse as a species is rather resistant to the development of atherosclerosis (30,31), most of the current models of diabetic atherosclerosis are based on the induction of DM by various means in genetically-modified mice with a propensity to atherosclerosis.

\section{MOUSE MODELS OF TYPE 1-DIABETES COMBINED WITH ATHEROSCLEROSIS}

\subsection{Streptozotocin treatment}

Numerous animal models of type 1-DM and CVD are based on treatment with streptozotocin (STZ), a monofunctional nitrosourea derivative isolated from Streptomyces achromogenes with cytotoxic effects on pancreatic $\beta$-cells $(32,33)$. However, it is important to note that the action of STZ is not restricted to $\beta$-cells (33). Rats and dogs treated with STZ develop DM but display increased levels of protein kinase C (PKC) and diacilglycerol (DAG) in the heart and aorta; administration of insulin normalized gluclose levels in plasma and prevented the concomitant increases in PKC and DAG $(34,35)$. These findings suggest that chronic activation of the PKC-DAG pathway by hyperglycemia facilitates the development of diabetic vascular complications.

Kunjathoor et al. investigated the effect of STZ-induced diabetes on atheroma development in two different strains of mice (C57BL/6 and BALB/e) fed either rodent chow or an atherogenic-promoting diet for 12-20 weeks (36). Regardless of strain and dietary regimen, STZ treatment caused sustained hyperglycemia and a modest reduction in plasma insulin levels. Whereas normoglycemic and hyperglycemic fat-fed C57BL/6 mice displayed fatty streak aortic sinus lesions of similar size, hyperglycemic BALB/c mice fed the atherogenic diet displayed a 17-fold increase in the area of atherosclerotic lesions as compared with normoglycemic fat-fed BALB/c controls. Moreover, correlations were noted between lesion size and plasma glucose levels in the BALB/c strain and between lesion size and plasma cholesterol in C57BL/6 mice. Based on these observations, the authors of this study suggest that hyperglycemia as opposed to hyperinsulinemia contributes heavily to risk of atherosclerosis.

Several laboratories have studied the effect of STZ treatment on genetically-modified mice with a strong predisposition to atherosclerosis. Mice deficient for apolipoprotein E (apoE-KO), which develop severe hypercholesterolemia and spontaneous atherosclerosis on a normal chow diet $(37,38)$, exhibit accelerated atherosclerosis when DM is induced by STZ (39). This is associated with increased macrophage-foam cell formation as measured by the cell lipid peroxidation and capacity to take up oxidized LDL (oxLDL). This may be caused by a direct effect of hyperglycemia on macrophages which exhibit a glucosedependent elevation of peroxide content and increased oxLDL uptake associated with induction of the mRNA for scavenger receptor CD36 (40).

STZ-induced type 1-DM has also been superimposed on mice deficient for the LDL receptor (LDLR-KO), which develop hyperlipidemia and atherosclerosis when challenged with a Western-type diet (41). Reaven et al. (42) fed LDLR-KO mice with a diet containing $0.75 \%$ cholesterol. Mice were left untreated or received STZ and a low-dose of insulin to prevent excessive mortality and extreme elevations in TG. After six months of high-fat feeding, diabetic STZ-treated LDLR-KO mice exhibited enhanced arterial production of advanced glycation end (AGE) products and higher levels of blood glucose and VLDL cholesterol as compared with non-diabetic controls. However, the degree of aortic atherosclerosis was similar in both groups of mice, suggesting that hyperglycemia and enhanced AGE formation do not contribute significantly to atherogenesis in LDLR-KO mice. In marked contrast, subsequent studies by Keren et al. (43) and Vikramadithyan et al. (44) have reported that STZ-treated LDLR-KO mice placed for 6-12 weeks on a high-fat diet exhibit higher levels of plasma glucose, cholesterol and TG and develop larger atherosclerotic lesions in the aortic root than non-diabetic controls $(43,44)$. These discrepancies may be related to different dietary regimens (e.g., long versus short time of fat-feeding) and/or a possible protective action of the low-dose insulin treatment used by Reaven et al. (42). Keren et al. (43) demonstrated that both humoral and cellular immune responses to heat shock protein 65 (HSP65) were more pronounced in STZ-injected LDLR-KO mice, and splenocytes from these animals displayed increased production of the T-helper (Th)-1 cytokine $\gamma$-interferon when challenged in vitro with HSP65. On the other hand, Vikramadithyan and co-workers (44) found that aortic atherosclerosis was further increased in STZ-treated LDLR-KO mice overexpressing the human aldose reductase, and peritoneal macrophages from these mice expressed more scavenger receptors and had a greater uptake of modified lipoproteins than non-transgenic controls. The results of this study confirm the notion that hyperglycemia is toxic to larger arteries and suggest that aldose reductase might modify this pathological response. 
Kako et al. crossed transgenic mice expressing human apolipoprotein B (apoB) with mice heterozygous for lipoprotein lipase (LPL1) and/or with transgenic mice expressing human cholesteryl ester transfer protein (CETP) (45). These animals were generated to create a more human-like lipoprotein profile, given that expression of apoB is low and CETP is absent in wild-type mice. HuB/LPL1 mice displayed increased TG in VLDLs whereas triple mutant (HuB/LPL1/CETP) mice had decreased HDL and increased VLDL and IDL/LDL. Treatment with STZ did not alter lipid profiles or atherosclerosis in HuB or HuB/LPL1/CETP mice. However, STZ-treated HuB/LPL1 mice were more diabetic, severely hyperlipidemic due to increased cholesterol and TG in VLDL and IDL/LDL, and displayed more atherosclerosis. Thus, these results obtained with STZ-treated mice suggest that type 1-DM without hyperlipidemia does not accelerate atherosclerosis in this animal model.

\subsection{The GP transgenic:LDLR-KO mouse}

Oldstone and co-workers (46) generated transgenic mice which express the lymphocytic choriomeningitis virus (LCMV) glycoprotein (GP) as a self antigen under the control of the rat insulin promoter. Infection with LCMV triggers an immune reaction that specifically destroys the GP-expressing $\beta$-cells thus provoking rapidly the onset of type 1-DM. The subsequent breeding of these mice with LDLR-KO mice produced atherosclerosis-prone mice with type 1-DM (LDLR-KO:GP mice); analysis of this model has suggested that hyperglycemia and diabetes-associated lipid abnormalities have distinct effects on initiation and progression of atherosclerotic plaques $(47,48)$. When LDLR-KO:GP mice are fed standard chow, they develop hyperglycemia, but not lipid abnormalities, and display accelerated lesion initiation as well as increased arterial macrophage accumulation without augmented proliferation, suggesting that hyperglycemia may represent a primary stimulus for neointimal macrophage accumulation by inducing their recruitment. Interestingly, insulin treatment corrected the hyperglycemia and reduced the size of early lesions in chow-fed mice. Thus, atheroma initiation is increased by induction of DM and not from a toxic effect related to viral destruction of pancreatic islets. On the other hand, fat-fed LDLR-KO:GP mice exhibited hyperlipidemia and advanced lesions with augmented macrophage proliferation and extensive intralesional hemorrhages in a manner largely dependent on diabetes-induced dyslipidemia, since the degree of atherosclerosis was similar between hyperlipidemic diabetic and nondiabetic mice with comparable plasma cholesterol levels. Lamharzi et al. (48) have suggested that the induction of macrophage proliferation by the concerted action of hyperglycemia and hyperlipidemia may involve glucose-oxidized LDL-mediated phosphorylation of extracellular signal-regulated kinase (ERK) and protein kinase B/Akt, and that this mitogenic effect of glucose-oxidized LDLs is mediated by CD36 and by protein kinase C- and phosphatidylinositol 3-
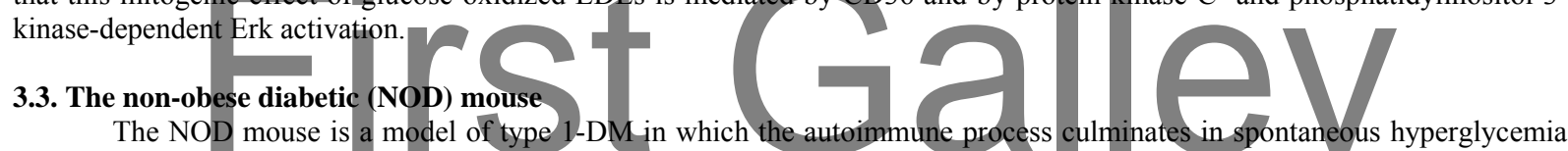
caused by the destruction of $\beta$-cell islets $(49,50)$. Keren and co-workers $(51)$ found that two distinct formulations of Westerntype diet were insufficient to elicit atherosclerosis in the aortic sinus of diabetic and nondiabetic female NOD mice even in the presence of hyperlipidemia and increased susceptibility to copper induced LDL oxidation.

\section{MOUSE MODELS OF TYPE 2-DIABETES COMBINED WITH ATHEROSCLEROSIS}

Normal blood glucose levels are maintained by a balance between glucose absorption in the gastro-intestinal tract, production by the liver and uptake by peripheral tissues, all of which are regulated by insulin signaling through the insulin receptor (INSR) (52). Dysregulation of these physiological processes leads to insulin resistant states and increased post-pandrial glucose and lipid levels. A detailed discussion of knockout models which have provided novel insights into insulin action and the development of insulin resistance and DM is beyond the scope of this review and can be found elsewhere (53). This section discusses available mouse models of type 2-DM and atherosclerosis which are based either on the use of 'diabetogenic' and 'atherogenic' diets, naturally occurring mutations which induce obesity and diabetes, genetically-modified mice, or a combination of the above (Table 3 ).

\subsection{Diabetogenic diets to induce atherosclerosis in susceptible mouse strains}

Several studies have suggested that both genetic and dietary factors determine susceptibility to obesity and type 2-DM. For example, while C57BL/6 mice develop obesity, hyperglycemia, hyperinsulinemia and insulin resistance when challenged with a diabetogenic diet enriched in fat and sucrose (54-56), A/J mice maintained on the same dietary regimen are resistant to the weight gain and metabolic perturbations noted in C57BL/6 mice (57). On the other hand, Schreyer et al. (58) found that maintenance on an atherogenic diet (enriched with fat and cholesterol) for 14 weeks did not induce hyperglycemia, hyperinsulinemia or obesity in strains $\mathrm{C} 57 \mathrm{BL} / 6, \mathrm{C} 3 \mathrm{H} / \mathrm{He}, \mathrm{BALB} / \mathrm{c}$ nor in seven recombinant inbred strains. Moreover, this study did not reveal any significant correlation between susceptibility to atherosclerosis and fasting insulin or glucose levels, or glucose clearance following short-term insulin or glucose treatment. These authors also found that a diabetogenic diet enriched in fat and sucrose but lacking cholesterol and bile acids induced obesity, diabetes and 2-fold increases in plasma lipoprotein concentrations in C57BL/6 mice. Remarkably, $40 \%$ of C57BL/6 mice fed the diabetogenic diet exhibited small aortic fatty streaks that were not observed in mice fed standard rodent chow. Because diabetic C57BL/6 mice developed both hyperglycemia and hyperinsulinemia, it is not possible to attribute aortic atheroma development to one particular diabetic parameter. Thus, it is unclear from these studies whether atherosclerosis induced by the diabetogenic diet was a consequence of increased plasma lipids or the diabetic metabolism, or a combination of both. It is also noteworthy that the atherogenic and diabetogenic diets had 
differential effects on the lipid profiles of C57BL/6 mice, thus suggesting that different dietary components regulate lipid transport genes in distinct ways.

Dietary studies in the atherosclerosis-prone LDLR-KO and apoE-KO mouse models have yielded confusing results. Merat et al. (59) analyzed the effects of a fructose-rich diet, a fat-enriched (Western), or standard chow diet on male C57BL/6x129SV ( $5^{\text {th }}$ generation backcrossed) LDLR-KO mice. Compared to the chow-fed group, mice fed either experimental diet during 5.5 months developed high hypercholesterolemia, but increased body weight, insulin resistance and hyperinsulinemia were only induced by the Western diet. Surprisingly, these insulin-resistant mice had significantly less atherosclerosis than the non-insulin-resistant, fructose-fed mice, thus indicating that insulin resistance and hyperinsulinemia do not enhance atherosclerosis in severely hypercholesterolemic male LDLR-KO mice. On the other hand, Schreyer et al. $(56,60)$ noted that feeding a fat- and sucrose-enriched diet for 16 weeks produced the largest effects on adiposity, hyperglycemia, hypertriglyceridemia, hypercholesterolemia, and hyperleptinemia in male LDLR-KO compared with wild-type mice (both C57BL/6 strain); atherosclerotic lesions in diabetogenic diet-fed LDLR-KO mice were increased 3.7-fold over chow fed values. These authors also included in their studies male C57BL/6 apoE-KO mice fed a diabetogenic diet which were resistant to changes in glucose and lipid homeostasis and to accelerated atherosclerosis despite the development of obesity. Discrepancies between the studies of Merat et al. (59) and Schreyer et al. $(56,60)$ might be related to different genetic backgrounds of the mouse strains utilized (mixed C57BL/6x129SV versus pure C57BL/6), and/or differences related to the carbohydrate composition in the experimental diets (sucrose-rich versus fructose-rich). Nevertheless, taken all together, these findings demonstrate that the metabolic alterations induced by the loss of LDLR or apoE have profound and distinct consequences on the propensity to develop dyslipemia, diet-induced obesity and type 2-DM phenotypes and on susceptibility to atherosclerosis in C57BL/6 male mice.

\subsection{Lipocalin-type prostaglandin $D(2)$ synthase (L-PGDS)-deficient mice}

Upregulation of the L-PGDS protein in patients with type 2-DM and atherosclerosis has been suggested as a protective mechanism to alleviate the cardiovascular problems associated with DM. Ragolia et al. (61) found that L-PGDS-null mice become glucose intolerant and develop insulin resistance at an accelerated rate compared to the C57BL/6 control strain. L-PGDSnull mice have larger adipocytes than controls, and cultured wild-type and L-PGDS-deficient VSMCs exhibit insulin-stimulated differences in mitogen-activated protein kinase phosphatase-2, protein tyrosine phosphatase-1D, and phosphorylated focal adhesion kinase expression levels. Rernarkably, feeding a diabetogenic high fat diet for 20 weeks provoked nephropathy and an aortic thickening reminiscent of the early stages of atherosclerosis only in L-PGDS-deficient mice. Thus, a thorough characterization of the L-PGDS-null mouse may yield significant insight into the mechanisms underlying insulin resistant- and DM-related atherosclerosis and nephropathy.

\subsection{Gold thioglucose (GTG)-induced obesity-related type 2-diabetes in the apoE-KO mouse model}

Obesity and insulin resistance can be induced in the mouse by a single peripheral injection of GTG, a neurotoxic glucose analogue which rapidly destroys within 24 hours leptin receptor-positive hypothalamic neurons, including those that regulate energy expenditure and food intake (satiety) (62). Lyngdorf et al. (63) have analyzed the consequences of GTG injection on atherosclerosis development in female apoE-KO mice fed ad libitum standard rodent chow. Based on their body weight progression after injection, mice were classified into two groups: non-responders $(n=10)$ which followed a growth curve similar to that of control mice, and responders $(\mathrm{n}=12)$ which displayed a marked long-term weight gain. Additional features of type 2DM in the GTG-sensitive mice included insulin resistance, hyperinsulinemia, hyperglycemia and hypertriglyceridemia. Paradoxically, obese and diabetic GTG-responding apoE-KO mice developed less atherosclerosis than either lean GTG-nonresponders or saline-injected ad libitum fed apoE-KO mice. Based on these findings, Lyngdorf et al. have raised concerns regarding the usefulness of mouse models in studying the relation of obesity-related type 2-DM to atherosclerosis. However, although the destruction of hypothalamic neurons is the only known action of GTG, the possibility that diminished atherosclerosis in GTG-responding mice reflects systemic effects of this drug cannot be excluded.

\subsection{Leptin receptor-deficient $\left(\mathrm{Lepr}^{\mathrm{db} / \mathrm{db}}\right)$ and leptin-deficient $\left(\mathrm{Lep}^{\mathrm{ob} / \mathrm{ob}}\right)$ mouse models}

The spontaneous autosomal recessive diabetes mutation $(\mathrm{db})$ was first detected in progeny of the $\mathrm{C} 57 \mathrm{BL} / \mathrm{KsJ}$ strain at the Jackson Laboratory (64), and animals with the same phenotype were subsequently described and named obese (ob) mice (65). It has been established that $o b$ and $d b$ encode for leptin and its receptor, respectively (65-67). Mice homozygotes for $d b$ (Lepr ${ }^{\mathrm{db} / \mathrm{db}}$ ) and $o b\left(\mathrm{Lep}^{\mathrm{ob} / \mathrm{ob}}\right)$ mutations display similar obesity-diabetes phenotypes, including early-onset obesity, extreme insulin resistance, more efficient conversion of food to lipid and a slower rate of catabolism on fasting $(64,65,68)$. These spontaneous mutations convey a selective advantage for heterozygous $\mathrm{db} /+$ and $\mathrm{ob} /+$ mice, as they survived a prolonged fast significantly longer than normal homozygotes $(+/+)$ and did not display pathological manifestations when food was abundant in populations subjected to alternating periods of supply and deprivation (68). It has been recently shown that ablation of ghrelin improves the diabetic but not obese phenotype of Lep ${ }^{\text {ob/ob }}$ mice (69).

Hasty and co-workers (70) were the first to report augmented aortic atherosclerosis in the double mutants $\mathrm{Lep}^{\mathrm{ob} / \mathrm{ob}}$ :LDLR-KO maintained on normal chow as compared with different control groups: wild-type, LDLR-KO, Lep ${ }^{\mathrm{ob} / \mathrm{ob}}$ and $\mathrm{Lep}^{\mathrm{ob} / \mathrm{ob}}:$ LDLR+/- mice. This phenotype of Lep ${ }^{\mathrm{ob} / \mathrm{ob}}:$ LDLR-KO mice was accompanied by severe hypercholesterolemia and hypertriglyceridemia caused by a large increase in apoB-containing broad- $\beta$ remnant lipoprotein fraction. These authors provided 
evidence to suggest that hypertriglyceridemia and hypercholesterolemia in the double mutant Lep $\mathrm{ob}^{\mathrm{ob}}:$ LDLR-KO mice are caused by distinct mechanisms and that leptin might have some impact on plasma cholesterol metabolism, possibly through an LDLRindependent pathway. They concluded that LDL cholesterol is a stronger atherogenic risk factor than are the combined effects of obesity, DM and insulin resistance when mice are fed a normal diet.

Liang et al. (71) found increased CD36 protein expression in thioglycollate-elicited peritoneal macrophages (TGEPM) from Lep ${ }^{\mathrm{ob} / \mathrm{ob}}$ mice, possibly caused by defective insulin signaling. This was associated with increased binding and uptake of oxLDL and acetylated LDL (acLDL) in vitro, thus suggesting a mechanism that might contribute to augmented foam cell formation and accelerated atherosclerosis in insulin resistant and DM pathological states. Consistent with this notion, in vivo administration of PPAR- $\gamma$ activators to Lep ${ }^{\mathrm{ob} / \mathrm{ob}}$ macrophages improved insulin resistance, decreased CD36 protein expression and diminished oxLDL uptake (71). Kjerrulf et al. (72) also reported increased CD36 expression and acLDL uptake in TGEPMs using this same model. Surprisingly, these authors found diminished expression of CD36 (and SR-A) and reduced acLDL uptake and cholesterol ester accumulation in cultures of $\mathrm{Lep}^{\mathrm{ob} / \mathrm{ob}}$ resident peritoneal macrophages, thus highlighting important differences between these two common sources of macrophages.

Gruen et al. (73) performed an exhaustive comparison of Lep ${ }^{\mathrm{ob} / \mathrm{ob}}:$ LDLR-KO and Lep ${ }^{\mathrm{ob} / \mathrm{ob}}:$ apoE-KO mice maintained on standard rodent chow. Compared to simple mutant control mice, body and fat pad weight and total plasma cholesterol levels were increased to the same extent in both models of double mutant mice. Interestingly, neither model showed increased plasma glucose. Lep ${ }^{\mathrm{ob} / \mathrm{ob}}:$ apoE-KO and Lep ${ }^{\mathrm{ob} / \mathrm{b}}:$ :LDLR-KO mice transported cholesterol primarily on VLDL and on LDL, respectively. Other differences included lower (55\%) TGs and higher non-esterified fatty acid (NEFA) (1.5-fold) and insulin (1.7-fold) levels in the plasma of Lep ${ }^{\mathrm{ob} / \mathrm{ob}}$ :apoE-KO mice. Atherosclerosis in Lep ${ }^{\mathrm{ob} / \mathrm{ob}}$ :apoE-KO and Lep ${ }^{\mathrm{ob} / \mathrm{ob}}:$ LDLR-KO mice was enhanced compared to single mutant apoE-KO and LDLR-KO controls. Remarkably, both aortic atheroma size (3.2-fold) and collagen content (7.7-fold) were increased in Lep $\mathrm{p}^{\mathrm{ob} / \mathrm{ob}}$ :apoE-KO compared to Lep $\mathrm{p}^{\mathrm{ob} / \mathrm{ob}}:$ LDLR-KO mice. Lesion burden was not associated with total plasma cholesterol and TG nor with individual lipoprotein pools in either animal model. In contrast, atheroma size was positively correlated with body weight and NEFA only in Lep ${ }^{\mathrm{ob} / \mathrm{ob}}$ :LDLR-KO mice, and with plasma insulin in both mouse models. Thus, despite the significant differences in atheroma size between leptin-deficiency in LDLR-KO vs. apoE-KO, these results support the notion that several typical features of DM (hyperinsulinemia, increased body weight and elevated plasma levels of NEFA) aggravate atherosclerosis in the mouse, even in the absence of hyperglycemia.

Wu et al. (74) reported that Lepr ${ }^{\mathrm{db} / \mathrm{db}}$ :apoE-KO mice exhibit features of the metabolic syndrome and type 2-DM, including obesity, hyperglycemia, hyperinsulinemia and dyslipidemia. When fed a regular chow diet, aortic lesion size and lipid content were increased in Lepr ${ }^{\mathrm{db} / \mathrm{db}}$ :apoE-KO mice compared to age-matched apoE-KO littermates. Atherosclerosis in $\mathrm{Lepr}^{\mathrm{db} / \mathrm{db}}$ :apoE-KO mice was further aggravated by fat feeding. More recently, Wendt et al. (75) have also noted accelerated aortic atherosclerosis in diabetic Lepr ${ }^{\mathrm{db} / \mathrm{db}}$ :apoE-KO mice fed normal chow as compared with non-diabetic controls.

Lepr $^{\mathrm{db} / \mathrm{db}}$ mice fed regular chow displayed a prominent peak in the LDL range, consisting almost exclusively of sdLDL, that was absent in non-diabetic controls, although HDL was the predominant species in both groups of mice (76). Upon administration of a Western type diet, the size distribution of lipoproteins was unchanged in control mice whereas fat-fed Lepr $^{\mathrm{db} / \mathrm{db}}$ mice develop a marked hypercholesterolemic response which was the result of a massive increase in the LDL region, characterized by persistent, sdLDLs and the appearance of larger particles which overshadowed a moderate increase in HDL. Due to similarities with the lipid profile of patients with type 2-DM, the authors of these studies have suggested the usefulness of fat-fed Lepr ${ }^{\mathrm{db} / \mathrm{db}}$ mice as a model to investigate the pathogenesis and treatment of diabetic dyslipidemia.

Gruen et al. (77) found that both Lep ${ }^{\mathrm{ob} / \mathrm{ob}}$ and Lepr ${ }^{\mathrm{d} b / \mathrm{db}}$ mice display increased plasma HDL levels and accumulate a unique lipoprotein referred to as LDL/HDL1. By analyzing the phenotype of apolipoprotein A-I-deficient (apoA-I-KO) mice homozygous for either the $d b$ or the $o b$ mutation, these authors demonstrated that these obese apoA-I-KO mice had dramatically decreased levels of HDL, although the LDL/HDL1 particle persisted as small LDLs and large HDLs. Moreover, they provide evidence suggesting that the maturation and removal of large HDLs depends on the integrity of a functional axis consisting of apoA-I, hepatic lipase, and scavenger receptor class B type I (SR-BI).

In a recent study, Li et al. (78) observed enhanced proatherogenic responses in both short-term cultured VSMCs and macrophages derived from obese, insulin-resistant and diabetic Lepr ${ }^{\mathrm{db} / \mathrm{db}}$ mice, including increased expression of cyclooxygenase2 and 12/15 lipoxygenase as well as key inflammatory cytokines and chemokines (e. g., IL-1 $\beta$, IL-6, IL-8, IL-12, TNF $\alpha$, MCP-1, and IP-10), increased oxidant stress, and activation of key signaling kinases (e. g., Src, ERK1/2, Akt, p38) and transcription factors involved in the regulation of atherogenic and inflammatory genes (e. g., cAMP response element-binding protein, nuclear factor- $\mathrm{KB}$ ). Remarkably, aortas derived from $\operatorname{Lepr}^{\mathrm{db} / \mathrm{db}}$ mice also exhibited increased expression of inflammatory genes, and VSMCs from these animals had enhanced migratory activity and adhesion to monocytes.

\subsection{Defective insulin signaling and atherosclerosis: Insulin receptor and insulin receptor substrate 2-null mice}

The INSR is a cell surface receptor that belongs to the family of growth factor receptor tyrosine kinases. The propagation of the signal generated by insulin through the insulin receptor substrate (IRS)/phosphatidylinositol 3-kinase (PI3K) pathway plays a key role in glucose and lipid metabolism. Among other effects, activation of the serine-threonine kinase Akt stimulates 
glycogen synthesis and inhibits lipolysis while PKC activation has been linked to accumulation of TGs in micells, a hallmark of insulin resistance (79). INSR-null mice exhibit growth retardation, a progressive increase in glucose levels and severe hyperinsulinemia. Within a few days of birth, pancreatic beta cell failure is followed by death of the animals caused by diabetic ketoacidosis (80). The severity of this phenotype indicates that the INSR plays a major role in postnatal glucose homeostasis $(79,80)$.

IRS proteins mediate the majority of metabolic and growth-promoting actions of insulin and IGF-1 and play a critical role in the regulation of beta cell function and in the maintenance of glucose homeostasis (81). Analysis of mice deficient for the four IRS genes has provided important information about the signaling mechanisms regulated by insulin (82). IRS-1 deletion in mice retards somatic growth and produces mild insulin resistance without type 2-DM $(83,84)$. Insulin signaling in liver is normal in IRS-1-KO mice suggesting that is mainly regulated by IRS-2 (85). Disruption of the IRS-2 gene produces female infertility and pathological alterations very similar to type 2-DM and metabolic syndrome, including insulin resistance, hyperinsulinemia, glucose intolerance, hypertension, and moderate hyperlipidemia (86-88). At 6-8 weeks of age, male IRS-2-KO mice exhibit severe diabetes as the reduced $\beta$-cell mass fails to produce sufficient insulin $(86,87)$. Furthermore, deletion of IRS-2 produces female obesity owing to a dysregulation of appetite and leptin sensitivity, demonstrating that IRS-2 is required for central regulation of nutrient homeostasis and obesity (88-90). The importance of IRS- 2 signals for the development of pancreatic $\beta$-cells and $\beta$-cell function has been further established by generation of RIP-IRS2 transgenic mice; overexpression of IRS-2 specifically in the pancreas of IRS-2-deficient mice and Lep ${ }^{\mathrm{ob} / \mathrm{ob}}$ mice restored $\beta$-cell mass and thus, glucose tolerance (91). In contrast to the phenotypes of IRS-1-KO and IRS-2-KO mice, deficiency for either IRS-3 or IRS-4 does not appear to alter growth or metabolism in the mouse (92-95).

Disruption of insulin signaling specifically in macrophages has been used recently to evaluate the role of this pathway in macrophage foam cell formation and diabetes-accelerated atherosclerosis. Transplantation of INSR-null bone marrow into irradiated LDLR-KO mice increased lipid uptake through the upregulation of CD36 and SRA, thereby aggravating atherosclerosis (96). In agreement with this study, previous studies in mice (71) and humans $(97,98)$ have linked defective insulin signaling to increased lipid accumulation in macrophages and foam cell formation via enhanced CD36 receptor expression. By contrast, Baumgartl and co-workers (99) reported that macrophage-specific deficiency of either INSR or IRS-2 ameliorates atherosclerosis development in apoE-KO mice. Although the reasons for this apparent discrepancy are unclear, it appears that modulation of glucose and insulin signaling in macrophages plays a direct role in lipid deposition and foam cell formation in the vessel wall.

Global IRS-2 deficiency in fat-fed apoE-KO mice aggravates atherosclerosis compared with apoE-KO mice with intact IRS-2, although both models displayed similar levels of hypercholesterolemia $(\sim 2500 \mathrm{mg} / \mathrm{dL}$ in Baumgartl et al. $(99)$ and $>600$ $\mathrm{mg} / \mathrm{dL}$ in González-Navarro et al. (100)). Clough et al. (101) also found accelerated atherosclerosis in apoE-KO mice heterozygous for IRS-2. In contrast, atherosclerotic lesions were undetectable in fat-fed hyperglycemic and mildly hypercholesterolemic ( $280 \mathrm{mg} / \mathrm{dL})$ IRS-2-KO mice with intact apoE (100). Although both Baumgartl et al. (99) and GonzálezNavarro et al. (100) reported impaired glucose tolerance in apoE-IRS-2-KO mice, only the former found significantly elevated fasting blood glucose concentration in these animals. On the other hand, circulating insulin levels predicted atherosclerotic lesion burden in apoE-IRS-2-KO mice (100), as previously reported in Lep ${ }^{\mathrm{ob} / \mathrm{ob}}:$ LDLR-KO and Lep ${ }^{\mathrm{ob} / \mathrm{ob}}$ :apoE-KO mice (73). These results suggest that hyperinsulinemia resulting from IRS-2-deficiency contributes to increased atherosclerosis when combined with severe hypercholesterolemia even in the absence of overt hyperglycemia (apoE-IRS-2-KO mice). Thus, these observations implicate IRS-2 as an important modulator of murine hypercholesterolemia-dependent atherosclerosis. Future studies are necessary to determine whether IRS-2 dysfunction may promote atherosclerosis in normoglycemic, pre-diabetic patients with clinical manifestations of hyperinsulinemia and insulin resistance.

\section{ANIMAL MODELS TO STUDY THE EFFECTS OF ALTERED LEPTIN/GLUCOSE/INSULIN SIGNALING ON NEOINTIMAL THICKENING INDUCED BY MECHANICAL INJURY OF THE VESSEL WALL}

Patients with DM are particularly prone to vessel re-narrowing (restenosis) after successful revascularization by percutaneous transluminal angioplasty and stent implantation (102-106). This section discusses the results of animal studies designed to investigate the effects of altered leptin, glucose, and/or insulin signaling on the development of obstructive neointimal lesions as induced by endovascular mechanical injury (Table 4).

\subsection{Type 1-diabetes models}

Different studies have yielded seemingly controversial results on the role of type 1-DM on mechanically-induced neointimal thickening. On the one hand, studies in alloxan-induced diabetic rabbits (107) and BB Wistar diabetic rats (108) demonstrated increased neointima development after balloon angioplasty of the carotid artery and aorta, respectively, compared with nondiabetic controls. In contrast, neointimal lesion size was unchanged after endovascular injury of the femoral artery of ins $2^{\text {Akita }}$ mice (109) and aorta of STZ-treated Sprague-Dawley rats (110), or even reduced in the carotid artery of hyperglycemic STZ-induced diabetic Wistar rats (111).

5.2. Lepr $^{\mathrm{db} / \mathrm{db}}$ mice 
As indicated above, obese type 2 diabetic doubly mutant $\mathrm{Lep}^{\mathrm{db} / \mathrm{db}}$ :apoE-KO mice exhibit accelerated atherosclerosis (74). Surprisingly, neointimal formation after angioplasty was attenuated by approximately $90 \%$ in Lep ${ }^{\mathrm{db} / \mathrm{db}}$ compared with nondiabetic wild-type mice (109). This phenotype correlated with diminished medial VSMC death at four hours after injury, but neointimal proliferation at two weeks post-injury appeared unaffected. It is noteworthy that arterial injury studies in the obese Zucker rats carrying a mutated leptin receptor have not been consistent, with two studies showing a 2-fold increase in neointimal thickening $(110,112)$ and another study reporting no changes in lesion development in these animals compared with lean controls $(113)$. Further studies are thus required to unravel the relationship between leptin function and neointimal thickening in the setting of mechanical vascular injury and atherosclerosis in dyslipidemic animals.

\subsection{IRS-deficient mice}

Using the femoral artery cuff placement model of vascular injury (114), Kubota et al. (115) examined the effects of IRS1 and IRS-2 deficiency on neointimal thickening. At both 8 and 20 weeks of age, the absence of IRS-2 markedly increased neointima formation (1.5-fold and 2.3-fold increase versus wild-type mice, respectively). In contrast, neointimal thickening was unchanged in 8-week-old IRS-1-KO and augmented only by 1.6-fold at 20 weeks of age as compared with wild-type mice. Based on the results of Western blot analysis, these authors have suggested that reduced IRS-2 protein expression in vessel tissue might account for the mild increase in neointima formation in 20-week-old IRS-1-KO mice. Comparison of risk factors for atherosclerosis indicated that the observed differences in neointimal thickening may be directly related to metabolic abnormalities of IRS-2-KO versus IRS-1-KO mice at both 8 and 20 weeks, including hypertriglyceridemia, hypercholesterolemia, hyperinsulinemia, and hypertension. Moreover, hyperglucemia was only seen in 20-week-old IRS-2-KO mice. This study provides the first evidence that intact IRS-2 signaling may protect against the development of neointimal lesions induced by mechanical injury.

\subsection{Role of hyperinsulinemia}

Using the rat carotid artery model of balloon angioplasty, Indolfi et al. (111) reported that insulin therapy significantly increases neointima formation in hyperglycemic STZ-induced diabetic rats. This effect of exogenous insulin was abrogated upon inhibition of cellular ras by intraluminal adenovirus-mediated transfection of the N17H-ras-negative mutant gene. Hyperinsulinemia also increases neointimal thickening in balloon-injured arteries of nondiabetic rats, as revealed pancreatic islet transplantation (111) and insulin infusion (116) studies. Remarkably, VSMC migration and proliferation, two key events in neointimal thickening, are enhanced in vitro by insulin $(111,117)$

\section{EXPERIMENTAL THERAPIES FOR TREATING DIABETIC ATHEROSCLEROSIS} (Table 5)

In this section, the therapeutic approaches that efficiently suppress diabetic atherosclerosis in the mouse are discussed

\subsection{Inhibition of the AGE pathway}

Animal and human studies indicate that AGEs and their receptor (RAGE) are upregulated in the vasculature and atherosclerotic lesions of diabetic individuals (118). Park et al. (39) first reported that treatment of STZ-induced diabetic apoEKO mice with a soluble extracellular ligand-binding domain of RAGE (sRAGE) that binds up AGEs suppresses dosedependently diabetic atherosclerosis in a glycemia- and lipid-independent manner. Subsequently, Bucciarelli et al. (119) reported that sRAGE administration decreases parameters of inflammation and mononuclear phagocyte and VSMC activation and stabilizes established atherosclerotic plaques in the same animal model. Likewise, Forbes et al. (120) found that blockade of the RAGE-AGE axis by administration of the AGE cross-link breaker ALT-711, or the inhibitor of AGE formation aminoguanidine, reduced vascular AGE accumulation and diminished both plaque area and complexity in the thoracic and abdominal aortas of STZ-treated apoE-KO mice. Moreover, STZ-treated apoE-KO mice fed an AGE-enriched diet developed larger lesions at the aortic root than controls fed a low-AGE diet, in the absence of diet-related changes in plasma glucose, TGs, or cholesterol (121). Thus, in STZ-treated diabetic apoE-KO mice, AGE-RAGE interactions contribute to accelerated atherosclerosis independent of changes in levels of glucose, insulin or lipids. More recently, Wendt et al. (75) extended these concepts to a murine model of type 2-DM by demonstrating that treatment of diabetic Lepr ${ }^{\mathrm{db} / \mathrm{db}}$ :apoE-KO mice with sRAGE significantly reduces atherosclerosis in a glycemia- and lipid-independent manner. Administration of sRAGE to nondiabetic $\mathrm{Lepr}^{\mathrm{m} / \mathrm{db}}$ :apoE-KO controls also reduced atherosclerotic lesion area at the aortic sinus, suggesting that upregulation of RAGE ligands and RAGE occurs even in the nondiabetic, hyperlipidemic state. Similarly, sRAGE administration inhibited neointimal thickening after balloon angioplasty in both Zucker diabetic and nondiabetic rats, indicating that RAGE mediates neointimal formation in response to arterial injury (113). Interestingly, RAGE also seems to be involved in impairment of angiogenesis in diabetic mice (122).

\subsection{Blockade of the renin-angiotensin system}

Candido et al. (123) demonstrated that accelerated atherosclerosis in STZ-treated apoE-KO mice correlates with a significant increase in aortic angiotensin-converting enzyme (ACE) expression and activity, and connective tissue growth factor and vascular cell adhesion molecule-1 expression. Administration of the ACE inhibitor perindopril inhibited these pathological alterations. Subsequently, these researchers demonstrated that the angiotensin II subtype 1 (AT1) receptor blocker irbesartan, but not clinical doses of the calcium channel antagonist amlodipine, suppresses the upregulation of aortic AT1 receptor expression 
and diabetes-associated atherosclerosis (124). More recently, they have reported that combined ACE and neutral endopeptidase inhibition in STZ-treated apoE-KO mice by omapatrilat administration reduced atherosclerosis and protected the animals from renal structural injury and albuminuria (125). The ACE inhibitor quinapril was equally effective at inhibiting aortic ACE activity and reducing atherosclerosis, but the modest anti-hypertensive response of omapatrilat correlated with superior renal protection.

\subsection{Imatinib}

Imatinib (also known as Gleevec, STI-571, and CGP57148B) is a low molecular weight inhibitor of the protein tyrosine kinase activity of both platelet-derived growth factor receptor (PDGF-R) subtypes, as well as that of Abl, Bcr-Abl, and c-kit. This drug is currently being used clinically to successfully treat several forms of malignancies, in particular chronic myelogenous leukemia (126). Other therapeutic applications of imatinib have been demonstrated in animal models of vascular proliferative disease, including restenosis after balloon angioplasty (127), diet-induced atherosclerosis (128) and transplant atherosclerosis (129). Lassila et al. (130) found that imatinib treatment prevents the development of atherosclerotic lesions and diabetes-induced inflammatory cytokine overexpression in the aorta of STZ-treated apoE-KO mice, suggesting a therapeutic approach to retard the development of diabetes-associated atherosclerosis.

\section{4. $17 \beta$-estradiol}

Epidemiological data and animal studies indicate that estrogens markedly attenuate the risk of cardiovascular morbidity and death in premenopausal women (131). Using STZ-treated apoE-KO mice, Tse et al. (132) found that chronic administration of $17 \beta$-estradiol via a slow release pellet significantly decreased blood glucose and TG levels and effectively prevented diabeticrelated atherosclerosis and premature calcified cartilaginous metaplasia in the aorta.

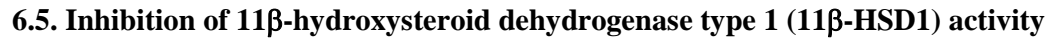

$11 \beta$-HSD1 raises the effective glucocorticoid tone above serum levels by converting cortisone into active cortisol in cells. Hermanowski-Vosatka et al. (133) reported that pharmacologic inhibition of 11ß-HSD1 with a competitive inhibitor for cortisone has salutary effects on multiple aspects of the metabolic syndrome in both Western-type diet-induced obese mice (lowered body weight gain, fat pad weight, and plasma levels of insulin, fasting glucose, TGs, and cholesterol) and type 2-DM murine models (DIO and HF/STZ mice) (lowered fasting plasma glucose, insulin, glucagon, TG, and FFA levels, as well as improved glucose tolerance). Moreover, $113-H S D 1$ inhibition reduced serum cholesterol and TGs, diminished aortic accumulation of total cholesterol and slowed plaque progression in fat-fed apoE-KO mice. Whether 11 $\beta$-HSD1 inhibition reduces diabetic atherosclerosis is not known.

\subsection{The thromboxane $A 2$ receptor antagonist $S 18886$}

DM is associated with increased thromboxane A2 (TXA2) and other eicosanoids that stimulate TP (TXA2 and prostaglandin endoperoxide) receptor. The orally active TP receptor antagonist S18886, which is in clinical development for use in secondary prevention of thrombosis in patients affected by CVD, has been shown to inhibit the development of atherosclerosis in rabbits (134) and apoE-KO mice (135). Moreover, S18886 lessens enhanced aortic atherogenesis caused by STZ-induced DM in female apoE-KO mice without affecting the associated increase in hyperglycemia or hypercholesterolemia (136). This salutary effect of S18886 correlated with inhibition of intimal markers of inflammation associated with DM and less deterioration of endothelial function and eNOS expression. Furthermore, S18886 abrogated the induction of vascular cell adhesion molecule-1 and prevented the decrease in eNOS expression caused by high glucose in cultured human aortic ECs.

\subsection{Peroxisome proliferator-activated receptor (PPAR) agonists}

PPAR- $\alpha, \gamma$, and $\beta / \delta$ are nuclear receptors that play major roles in the regulation of lipid metabolism, glucose homeostasis and inflammatory processes involved in the development of DM and atherosclerosis (137). Fibrates (e.g. fenofibrate, gemfizobril) are PPAR- $\alpha$ agonists which are primarily used for the treatment of dyslipidemia based on their efficacy at reducing TGs and increasing the levels of HDL-cholesterol and large buoyant, less-atherogenic LDL cholesterol particles (138). Administration of fenofibrate to diabetic Lepr ${ }^{\mathrm{db} / \mathrm{db}}$ :apoE-KO mice fed a Western type diet from 4 to 14 weeks of age reduced aortic atherosclerosis by 2.5 - and 5.3-fold, respectively. However, fenofibrate only reduced total plasma cholesterol by approximately $30 \%$, suggesting that this PPAR- $\alpha$ agonist may have a direct anti-atherogenic action on the vessel wall independently of its lipid lowering capacity (74). Likewise, gemfibrozil exerts anti-atherogenic effects in STZ-treated diabetic apoE-KO mice independently of significant changes in plasma glucose, glycated haemoglobin, cholesterol and insulin (139). This therapeutic effect of gemfibrozil correlated with the following changes in aortic tissue: 1) diminished expression of various $\mathrm{NAD}(\mathrm{P}) \mathrm{H}$ oxidase subunits and reduced superoxide production; 2) reduced expression of proinflammatory genes, RAGE, angiotensin II receptor subtype 1, and metalloproteinase 9.

Rosiglitazone, an insulin sensitizing PPAR- $\gamma$ agonist currently used for the treatment of type 2-DM patients, significantly attenuates atherosclerosis in STZ-treated diabetic apoE-KO mice (140); however, there were no significant changes in plasma glucose, insulin or cholesterol levels between treated and untreated diabetic mice. This inhibitory effect of rosiglitazone was associated with attenuated superoxide production, increased expression of the reverse cholesterol transport marker ABCA1 and reduced angiotensin II receptor gene expression in aortic tissue, and attenuated neointimal macrophage accumulation. These studies in the mouse suggest that PPAR- $\alpha$ and PPAR- $\gamma$ agonists confer vascular protection independent of their effects on 
glucose and lipid metabolism. These agents also attenuate diabetic kidney disease in STZ-treated apoE-KO mice (141). However, it is noteworthy that rosiglitazone appears to have little effect on cardiovascular endpoints in human (e.g. DREAM trial).

Zadelaar et al. have investigated the effect of the dual PPARalpha/gamma agonist tesaglitazar on atherosclerosis in insulin resistant and hypercholesterolemic ApoE*3Leiden transgenic mice (142). In fat-fed mice, tesaglitazar decreased plasma cholesterol by $20 \%$ compared with the HC group, caused a $92 \%$ reduction in atherosclerosis beyond that expected from cholesterol lowering, and induced a shift to less severe lesions with reduced number of adhering monocytes and macrophage-rich and collagen areas. Additionally, tesaglitazar inhibited the expression of inflammatory markers.

\subsection{Antioxidant therapy: polyphenols, $\alpha$-lipoic acid and paraoxonase 1 (PON1)}

It is becoming increasingly evident that hyperglycemia-induced oxidative stress contributes to atherosclerosis and associated cardiovascular complications in diabetic patients. Recent animal studies indicate that dietary antioxidants (e. g., polyphenols and $\alpha$-lipoic acid) may be a new therapeutic avenue for reducing diabetic atherosclerosis. Dietary polyphenols are natural antioxidants which appear to have beneficial effects on dyslipidemia and atherosclerosis (143). Several polyphenols, including resveratrol, apigenin, and S17834, induce the phosphorylation of AMP-activated kinase (AMPK) and its downstream target acetyl-CoA carboxylase (ACC) in cultured HepG2 hepatocytes (144). Moreover, the polyphenols prevented lipid accumulation induced by exposure of these cells to high glucose, whereas overexpression of constitutively active and dominantnegative AMPK mutants mimicked and abrogated these effects, respectively. Remarkably, S17834 administration to STZ-treated diabetic LDLR-KO mice inhibited hyperlipidemia and the acceleration of aortic lesion development, and this correlated with maintenance of AMPK and ACC phosphorylation and reduced accumulation of lipids in the liver (144). These observations suggest that hepatic AMPK inactivation plays an important role in the pathogenesis of hyperlipidemia in DM, and that polyphenols, by ameliorating dyslipidemia through AMPK activation, may ameliorate diabetic atherosclerosis.

Chronic treatment of fat-fed STZ-treated diabetic apoE-KO mice with the potent natural antioxidant $\alpha$-lipoic acid significantly lowered markers of oxidative stress and produced a reduction of plasma glucose and accelerated the recovery of pancreatic insulin-producing $\beta$-cells (145). These effects were accompanied by an attenuation of the increase in plasma total cholesterol, atherosclerotic lesions, and the general deterioration of health caused by DM.

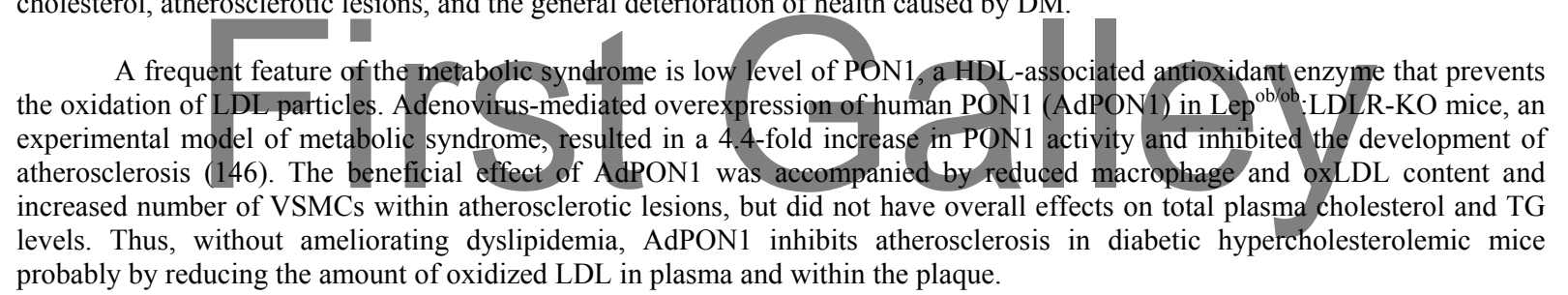

\section{CONCLUSIONS AND FUTURE PERSPECTIVES}

Clinical studies have firmly established that type 1- and type 2-DM are associated with an increased risk for CVD. Moreover, given that the incidence of DM is increasing dramatically in developed countries, it is of utmost importance to identify suitable animal models for unraveling the molecular mechanisms mediating diabetic atherosclerosis in order to facilitate the development of novel preventive and therapeutic strategies. As we discuss extensively throughout this review, accelerated atherosclerosis has been demonstrated in available mouse models of both type 1- and type 2-DM. In addition to yielding insights into the molecular connections between diabetic metabolism and CVD, these models serve as valuable tools for evaluating therapeutic strategies.

A frequent observation in murine studies is that DM per se does not promote atherosclerosis in the absence of dyslipidemia. Indeed, diabetic mice present also dyslipemia in the majority of experimental settings, thus making it difficult to differentiate between the effects of DM and those induced by aggravated lipid abnormalities. Although this may seem a limitation, it is noteworthy that deranged carbohydrate and lipid metabolism is a common feature in human diabetic patients, thus highlighting the relevance of available murine models of diabetic atherosclerosis. Several authors have attributed to hyperglycemia and hyperinsulinemia different importance in the development of accelerated atherosclerosis in type 1- and type 2-DM. Regardless of the peculiarities of different murine models, it appears certain that several features of type 2-DM/metabolic syndrome, including hyperinsulinemia, increased body weight and elevated plasma levels of NEFA, aggravate atherosclerosis in the mouse, even in the absence of hyperglycemia. On the other hand, it has been suggested that hyperglycemia may represent a primary stimulus of accelerated atherosclerosis in type 1-DM. Precisely how these aspects of diabetic metabolism predispose for the development of neointimal lesions has yet to be determined but clearly the possibility to perform biochemical and genetic manipulations in mouse models will provide the necessary tools to unravel the complex links between these important human diseases.

\section{ACKNOWLEDGEMENTS}

Work in the laboratory of the authors is supported by grants from the Spanish Instituto de Salud Carlos III (Red Temática de Investigación Cooperativa en Enfermedades Cardiovasculares RECAVA, Red de Grupos G03/212), and from the 


\section{Murine models of diabetic atherosclerosis}

Spanish Ministry of Education and Science and the European Regional Development Fund (SAF2004-03057, SAF2005-06058). H. G.-N. is supported by an European Union Marie Curie postdoctoral fellowship.

\section{REFERENCES}

1. Lusis A. J.: Atherosclerosis. Nature 407, 233-241. (2000)

2. Ross R.: Atherosclerosis: an inflammatory disease. $N$ Engl J Med 340, 115-126 (1999)

3. Glass C. K. \& J. L. Witztum: Atherosclerosis. the road ahead. Cell 104, 503-516 (2001)

4. Steinberg D.: Atherogenesis in perspective: hypercholesterolemia and inflammation as partners in crime. Nat Med 8, 1211$1217(2002)$

5. Binder C. J., M. K. Chang, P. X. Shaw, Y. I. Miller, K. Hartvigsen, A. Dewan \& J. L. Witztum: Innate and acquired immunity in atherogenesis. Nat Med 8, 1218-1226 (2002)

6. Greaves D. R. \& K. M. Channon: Inflammation and immune responses in atherosclerosis. Trends Immunol 23, 535-541 (2002)

7. Gerstein H. C. \& S. Yusuf: Dysglycaemia and risk of cardiovascular disease. Lancet 347, 949-950 (1996)

8. Beckman J. A., M. A. Creager \& P. Libby: Diabetes and atherosclerosis: epidemiology, pathophysiology, and management. Jama 287, 2570-2581 (2002)

9. Stolar M. W. \& R. J. Chilton: Type 2 diabetes, cardiovascular risk, and the link to insulin resistance. Clin Ther 25 Suppl B, B4-31 (2003)

10. Askari B., C. B. Renard \& K. E. Bornfeldt: Regulation of smooth muscle cell accumulation in diabetes-accelerated atherosclerosis. Histol Histopathol 17, 1317-1328 (2002)

11. Moreno P. R. \& V. Fuster: New aspects in the pathogenesis of diabetic atherothrombosis. J Am Coll Cardiol 44, 2293-2300 (2004)

12. Reaven G.: Why Syndrome X? From Harold Himsworth to the Insulin Resistance Syndrome. Cell Metabolism 1, 9-14 (2005)

13. Di Carli M. F. \& R. Hachamovitch: Should we screen for occult coronary artery disease among asymptomatic patients with diabetes? J Am Coll Cardiol 45, 50-53 (2005)

14. Zimmet P., K. G. Alberti \& J. Shaw: Global and societal implications of the diabetes epidemic. Nature 414, $782-787$ (2001)

15. Notkins A. L. \& A. Lernmark: Autoimmune type 1 diabetes: resolved and unresolved issues. J Clin Invest 108, 1247-1252 (2001)

16. Trucco M.: Regeneration of the pancreatic beta cell. J Clin Invest 115, 5-12 (2005)

17. Creusot R. J. \& C. G. Fathman: Gene therapy for type 1 diabetes: a novel approach for targeted treatment of autoimmunity. $J$ Clin Invest 114, 892-894 (2004)

18. Tian C., J. Bagley, N. Cretin, N. Seth, K. W. Wucherpfennig \& J. Iacomini: Prevention of type I diabetes by gene therapy. $J$ Clin Invest 114, 969-978 (2004)

19. Rhodes C. J.: Type 2 diabetes-a matter of beta-cell life and death? Science 307, 380-384 (2005)

20. Ginsberg H. N.: Insulin resistance and cardiovascular disease. J Clin Invest 106, 453-458 (2000)

21. Brunzell J. D. \& A. F. Ayyobi: Dyslipidemia in the metabolic syndrome and type 2 diabetes mellitus. Am J Med 115 Suppl 8A, 24S-28S (2003)

22. Ayyobi A. F. \& J. D. Brunzell: Lipoprotein distribution in the metabolic syndrome, type 2 diabetes mellitus, and familial combined hyperlipidemia. Am J Cardiol 92, 27J-33J (2003)

23. Kang H. S., B. Gutin, P. Barbeau, M. S. Litaker, J. Allison \& N. A. Le: Low-density lipoprotein particle size, central obesity, cardiovascular fitness, and insulin resistance syndrome markers in obese youths. Int J Obes Relat Metab Disord 26, 1030-1035 (2002)

24. Sibley S. D., J. P. Palmer, I. B. Hirsch \& J. D. Brunzell: Visceral obesity, hepatic lipase activity, and dyslipidemia in type 1 diabetes. J Clin Endocrinol Metab 88, 3379-3384 (2003)

25. Goff D. C., B. D'Agostino R, S. M. Haffner \& J. D. Otvos: Insulin resistance and adiposity influence lipoprotein size and subclass concentrations. Results from the Insulin Resistance Atherosclerosis Study. Metabolism 54, 264-270 (2005)

26. Evans M., N. Khan \& A. Rees: Diabetic dyslipidaemia and coronary heart disease: new perspectives. Curr Opin Lipidol 10, 387-391 (1999)

27. Schwartz S. M. \& K. E. Bornfeldt: How does diabetes accelerate atherosclerotic plaque rupture and arterial occlusion? Front Biosci 8, s1371-1383 (2003)

28. Steinberg H. O., H. Chaker, R. Leaming, A. Johnson, G. Brechtel \& A. D. Baron: Obesity/insulin resistance is associated with endothelial dysfunction. Implications for the syndrome of insulin resistance. J Clin Invest 97, 2601-2610 (1996)

29. Taguchi S., T. Oinuma \& T. Yamada: A comparative study of cultured smooth muscle cell proliferation and injury, utilizing glycated low density lipoproteins with slight oxidation, auto-oxidation, or extensive oxidation. J Atheroscler Thromb 7, 132-137 (2000)

30. Breslow J. L.: Mouse models of atherosclerosis. Science 272, 685-688 (1996)

31. Smithies O. \& N. Maeda: Gene targeting approaches to complex genetic diseases: atherosclerosis and essential hypertension. Proc Natl Acad Sci U S A 92, 5266-5272 (1995)

32. Like A. A. \& A. A. Rossini: Streptozotocin-induced pancreatic insulitis: new model of diabetes mellitus. Science 193, 415417 (1976)

33. Bolzan A. D. \& M. S. Bianchi: Genotoxicity of streptozotocin. Mutat Res 512, 121-134 (2002) 


\section{Murine models of diabetic atherosclerosis}

34. Inoguchi T., P. Xia, M. Kunisaki, S. Higashi, E. P. Feener \& G. L. King: Insulin's effect on protein kinase C and diacylglycerol induced by diabetes and glucose in vascular tissues. Am J Physiol 267, E369-379 (1994)

35. Xia P., T. Inoguchi, T. S. Kern, R. L. Engerman, P. J. Oates \& G. L. King: Characterization of the mechanism for the chronic activation of diacylglycerol-protein kinase C pathway in diabetes and hypergalactosemia. Diabetes 43, 1122-1129 (1994)

36. Kunjathoor V. V., D. L. Wilson \& R. C. LeBoeuf: Increased atherosclerosis in streptozotocin-induced diabetic mice. J Clin Invest 97, 1767-1773 (1996)

37. Zhang S. H., R. L. Reddick, J. A. Piedrahita \& N. Maeda: Spontaneous hypercholesterolemia and arterial lesions in mice lacking apolipoprotein E. Science 258, 468-471 (1992)

38. Plump A. S., J. D. Smith, T. Hayek, K. Aalto-Setälä, A. Walsh, J. G. Verstuyft, E. M. Rubin \& J. L. Breslow: Severe hypercholesterolemia and atherosclerosis in apolipoprotein E-deficient mice created by homologous recombination in ES cells. Cell 71, 343-353 (1992)

39. Park L., K. G. Raman, K. J. Lee, Y. Lu, L. J. Ferran, Jr., W. S. Chow, D. Stern \& A. M. Schmidt: Suppression of accelerated diabetic atherosclerosis by the soluble receptor for advanced glycation endproducts. Nat Med 4, 1025-1031 (1998)

40. Hayek T., K. Hussein, M. Aviram, R. Coleman, S. Keidar, E. Pavoltzky \& M. Kaplan: Macrophage-foam cell formation in streptozotocin-induced diabetic mice: Stimulatory effect of glucose. Atherosclerosis 183, 25-33 (2005)

41. Ishibashi S., J. L. Goldstein, M. S. Brown, J. Herz \& D. K. Burns: Massive xanthomatosis and atherosclerosis in cholesterolfed low density lipoprotein receptor-negative mice. J Clin Invest 93, 1885-1893 (1994)

42. Reaven P., S. Merat, F. Casanada, M. Sutphin \& W. Palinski: Effect of streptozotocin-induced hyperglycemia on lipid profiles, formation of advanced glycation endproducts in lesions, and extent of atherosclerosis in LDL receptor-deficient mice. Arterioscler Thromb Vasc Biol 17, 2250-2256 (1997)

43. Keren P., J. George, A. Shaish, H. Levkovitz, Z. Janakovic, A. Afek, I. Goldberg, J. Kopolovic, G. Keren \& D. Harats: Effect of hyperglycemia and hyperlipidemia on atherosclerosis in LDL receptor-deficient mice: establishment of a combined model and association with heat shock protein 65 immunity. Diabetes 49, 1064-1069 (2000)

44. Vikramadithyan R. K., Y. Hu, H. L. Noh, C. P. Liang, K. Hallam, A. R. Tall, R. Ramasamy \& I. J. Goldberg: Human aldose reductase expression accelerates diabetic atherosclerosis in transgenic mice. J Clin Invest 115, 2434-2443 (2005)

45. Kako Y., M. Masse, L. S. Huang, A. R. Tall \& I. J. Goldberg: Lipoprotein lipase deficiency and CETP in streptozotocintreated apoB-expressing mide. J Lipid Res 43, 872-877 (2002)

46. Oldstone M. B., M. Nerenberg, P Southern, J. Price \& H. Lewicki: Virus infection triggers insulin-dependent diabetes mellitus in a transgenic model: role of anti-self (virus) immune response. Cell 65, 319-331 (1991)

47. Renard C. B., F. Kramer, F. Johansson, N. Lamharzi, L. R. Tannock, M. G. von Herrath, A. Chait \& K. E. Bornfeldt: Diabetes and diabetes-associated lipid abnormalities have distinct effects on initiation and progression of atherosclerotic lesions. J Clin Invest 114, 659-668 (2004)

48. Lamharzi N., C. B. Renard, F. Kramer, S. Pennathur, J. W. Heinecke, A. Chait \& K. E. Bornfeldt: Hyperlipidemia in concert with hyperglycemia stimulates the proliferation of macrophages in atherosclerotic lesions: potential role of glucose-oxidized LDL. Diabetes 53, 3217-3225 (2004)

49. Leiter E. H., M. Prochazka \& D. L. Coleman: The non-obese diabetic (NOD) mouse. Am J Pathol 128, 380-383 (1987)

50. Kikutani H. \& S. Makino: The murine autoimmune diabetes model: NOD and related strains. Adv Immunol 51, 285-322 (1992)

51. Keren P., J. George, G. Keren \& D. Harats: Non-obese diabetic (NOD) mice exhibit an increased cellular immune response to glycated-LDL but are resistant to high fat diet induced atherosclerosis. Atherosclerosis 157, 285-292 (2001)

52. Saltiel A. R. \& C. R. Kahn: Insulin signalling and the regulation of glucose and lipid metabolism. Nature 414, 799-806 (2001)

53. Plum L., F. T. Wunderlich, S. Baudler, W. Krone \& J. C. Bruning: Transgenic and knockout mice in diabetes research: novel insights into pathophysiology, limitations, and perspectives. Physiology (Bethesda) 20, 152-161 (2005)

54. Surwit R. S., C. M. Kuhn, C. Cochrane, J. A. McCubbin \& M. N. Feinglos: Diet-induced type II diabetes in C57BL/6J mice. Diabetes 37, 1163-1167 (1988)

55. Surwit R. S., M. F. Seldin, C. M. Kuhn, C. Cochrane \& M. N. Feinglos: Control of expression of insulin resistance and hyperglycemia by different genetic factors in diabetic C57BL/6J mice. Diabetes 40, $82-87$ (1991)

56. Schreyer S. A., C. Vick, T. C. Lystig, P. Mystkowski \& R. C. LeBoeuf: LDL receptor but not apolipoprotein E deficiency increases diet-induced obesity and diabetes in mice. Am J Physiol Endocrinol Metab 282, E207-214 (2002)

57. Surwit R. S., M. N. Feinglos, J. Rodin, A. Sutherland, A. E. Petro, E. C. Opara, C. M. Kuhn \& M. Rebuffe-Scrive: Differential effects of fat and sucrose on the development of obesity and diabetes in C57BL/6J and A/J mice. Metabolism 44, 645-651 (1995)

58. Schreyer S. A., D. L. Wilson \& R. C. LeBoeuf: C57BL/6 mice fed high fat diets as models for diabetes-accelerated atherosclerosis. Atherosclerosis 136, 17-24 (1998)

59. Merat S., F. Casanada, M. Sutphin, W. Palinski \& P. D. Reaven: Western-type diets induce insulin resistance and hyperinsulinemia in LDL receptor-deficient mice but do not increase aortic atherosclerosis compared with normoinsulinemic mice in which similar plasma cholesterol levels are achieved by a fructose-rich diet. Arterioscler Thromb Vasc Biol 19, 1223$1230(1999)$

60. Schreyer S. A., T. C. Lystig, C. M. Vick \& R. C. LeBoeuf: Mice deficient in apolipoprotein E but not LDL receptors are resistant to accelerated atherosclerosis associated with obesity. Atherosclerosis 171, 49-55 (2003) 


\section{Murine models of diabetic atherosclerosis}

61. Ragolia L., T. Palaia, C. E. Hall, J. K. Maesaka, N. Eguchi \& Y. Urade: Accelerated glucose intolerance, nephropathy and atherosclerosis in prostaglandin D2 synthase knockout mice. J Biol Chem (2005)

62. Le Marchand-Brustel Y.: Molecular mechanisms of insulin action in normal and insulin-resistant states. Exp Clin Endocrinol Diabetes 107, 126-132 (1999)

63. Lyngdorf L. G., S. Gregersen, A. Daugherty \& E. Falk: Paradoxical reduction of atherosclerosis in apoE-deficient mice with obesity-related type 2 diabetes. Cardiovasc Res 59, 854-862 (2003)

64. Hummel K. P., M. M. Dickie \& D. L. Coleman: Diabetes, a new mutation in the mouse. Science 153, 1127-1128 (1966)

65. Zhang Y., R. Proenca, M. Maffei, M. Barone, L. Leopold \& J. M. Friedman: Positional cloning of the mouse obese gene and its human homologue. Nature 372, 425-432 (1994)

66. Chua S. C., Jr., W. K. Chung, X. S. Wu-Peng, Y. Zhang, S. M. Liu, L. Tartaglia \& R. L. Leibel: Phenotypes of mouse diabetes and rat fatty due to mutations in the OB (leptin) receptor. Science 271, 994-996 (1996)

67. Chen H., O. Charlat, L. A. Tartaglia, E. A. Woolf, X. Weng, S. J. Ellis, N. D. Lakey, J. Culpepper, K. J. Moore, R. E. Breitbart, G. M. Duyk, R. I. Tepper \& J. P. Morgenstern: Evidence that the diabetes gene encodes the leptin receptor: identification of a mutation in the leptin receptor gene in $\mathrm{db} / \mathrm{db}$ mice. Cell 84, 491-495 (1996)

68. Coleman D. L.: Obesity genes: beneficial effects in heterozygous mice. Science 203, 663-665 (1979)

69. Sun Y., M. Asnicar, P. K. Saha, L. Chan \& R. G. Smith: Ablation of ghrelin improves the diabetic but not obese phenotype of ob/ob mice. Cell Metab 3, 379-386 (2006)

70. Hasty A. H., H. Shimano, J. Osuga, I. Namatame, A. Takahashi, N. Yahagi, S. Perrey, Y. Iizuka, Y. Tamura, M. AmemiyaKudo, T. Yoshikawa, H. Okazaki, K. Ohashi, K. Harada, T. Matsuzaka, H. Sone, T. Gotoda, R. Nagai, S. Ishibashi \& N. Yamada: Severe hypercholesterolemia, hypertriglyceridemia, and atherosclerosis in mice lacking both leptin and the low density lipoprotein receptor. J Biol Chem 276, 37402-37408 (2001)

71. Liang C. P., S. Han, H. Okamoto, R. Carnemolla, I. Tabas, D. Accili \& A. R. Tall: Increased CD36 protein as a response to defective insulin signaling in macrophages. J Clin Invest 113, 764-773 (2004)

72. Kjerrulf M., Z. Berke, A. Aspegren, M. Umaerus, T. Nilsson, L. Svensson \& E. Hurt-Camejo: Reduced cholesterol accumulation by leptin deficient (ob/ob) mouse macrophages. Inflamm Res 55, 300-309 (2006)

73. Gruen M. L., V. Saraswathi, A. M. Nuotio-Antar, M. R. Plummer, K. R. Coenen \& A. H. Hasty: Plasma insulin levels predict atherosclerotic lesion burden in obese hyperlipidemic mice. Atherosclerosis 186, 54-64 (2006)

74. Wu K. K., T. J. Wu, J. Chin, L. J. Mitnaul, M. Hernandez, T. Q. Cai, N. Ren, M. G. Waters, S. D. Wright \& K. Cheng: Increased hypercholesterolemia and atherosclerosis in mice lacking both ApoE and leptin receptor. Atherosclerosis 181, 251-259 (2005)

75. Wendt T., E. Harja, L. Bucciarelli, W. Qu, Y. Lu, L. L. Rong, D. G. Jenkins, G, Stein, A. M. Schmidt \& S. F. Yan: RAGE modulates vascular inflammation and atherosclerosis in a murine model of type 2 diabetes. Atherosclerosis 185, 70-77 (2006)

76. Kobayashi K., T. M. Forte, S. Taniguchi, B. Y. Ishida, K. Oka \& L. Chan: The $\mathrm{db} / \mathrm{db}$ mouse, a model for diabetic dyslipidemia: molecular characterization and effects of Western diet feeding. Metabolism 49, 22-31 (2000)

77. Gruen M. L., M. R. Plummer, W. Zhang, K. A. Posey, M. F. Linton, S. Fazio \& A. H. Hasty: Persistence of high density lipoprotein particles in obese mice lacking apolipoprotein A-I. J Lipid Res 46, 2007-2014 (2005)

78. Li S. L., M. A. Reddy, Q. Cai, L. Meng, H. Yuan, L. Lanting \& R. Natarajan: Enhanced Proatherogenic Responses in Macrophages and Vascular Smooth Muscle Cells Derived From Diabetic db/db Mice. Diabetes 55, 2611-2619 (2006)

79. Nandi A., Y. Kitamura, C. R. Kahn \& D. Accili: Mouse models of insulin resistance. Physiol Rev 84, 623-647 (2004)

80. Louvi A., D. Accili \& A. Efstratiadis: Growth-promoting interaction of IGF-II with the insulin receptor during mouse embryonic development. Dev Biol 189, 33-48 (1997)

81. Burks D. J. \& M. F. White: IRS proteins and beta-cell function. Diabetes 50 Suppl 1, S140-145 (2001)

82. Kadowaki T.: Insights into insulin resistance and type 2 diabetes from knockout mouse models. $J$ Clin Invest 106, 459-465 (2000)

83. Araki E., M. A. Lipes, M. E. Patti, J. C. Bruning, B. Haag, 3rd, R. S. Johnson \& C. R. Kahn: Alternative pathway of insulin signalling in mice with targeted disruption of the IRS-1 gene. Nature 372, 186-190 (1994)

84. Tamemoto H., T. Kadowaki, K. Tobe, T. Yagi, H. Sakura, T. Hayakawa, Y. Terauchi, K. Ueki, Y. Kaburagi, S. Satoh \& et al.: Insulin resistance and growth retardation in mice lacking insulin receptor substrate-1. Nature 372, 182-186 (1994)

85. Yamauchi T., K. Tobe, H. Tamemoto, K. Ueki, Y. Kaburagi, R. Yamamoto-Honda, Y. Takahashi, F. Yoshizawa, S. Aizawa, Y. Akanuma, N. Sonenberg, Y. Yazaki \& T. Kadowaki: Insulin signalling and insulin actions in the muscles and livers of insulinresistant, insulin receptor substrate 1-deficient mice. Mol Cell Biol 16, 3074-3084 (1996)

86. Withers D. J., D. J. Burks, H. H. Towery, S. L. Altamuro, C. L. Flint \& M. F. White: Irs-2 coordinates Igf-1 receptormediated beta-cell development and peripheral insulin signalling. Nat Genet 23, 32-40 (1999)

87. Kubota N., K. Tobe, Y. Terauchi, K. Eto, T. Yamauchi, R. Suzuki, Y. Tsubamoto, K. Komeda, R. Nakano, H. Miki, S. Satoh, H. Sekihara, S. Sciacchitano, M. Lesniak, S. Aizawa, R. Nagai, S. Kimura, Y. Akanuma, S. I. Taylor \& T. Kadowaki: Disruption of insulin receptor substrate 2 causes type 2 diabetes because of liver insulin resistance and lack of compensatory beta-cell hyperplasia. Diabetes 49, 1880-1889 (2000)

88. Burks D. J., J. F. de Mora, M. Schubert, D. J. Withers, M. G. Myers, H. H. Towery, S. L. Altamuro, C. L. Flint \& M. F. White: IRS-2 pathways integrate female reproduction and energy homeostasis. Nature 407, 377-382 (2000)

89. Lin X., A. Taguchi, S. Park, J. A. Kushner, F. Li, Y. Li \& M. F. White: Dysregulation of insulin receptor substrate 2 in beta cells and brain causes obesity and diabetes. J Clin Invest 114, 908-916 (2004)

90. Brady M. J.: IRS2 takes center stage in the development of type 2 diabetes. J Clin Invest 114, 886-888 (2004) 


\section{Murine models of diabetic atherosclerosis}

91. Hennige A. M., D. J. Burks, U. Ozcan, R. N. Kulkarni, J. Ye, S. Park, M. Schubert, T. L. Fisher, M. A. Dow, R. Leshan, M. Zakaria, M. Mossa-Basha \& M. F. White: Upregulation of insulin receptor substrate-2 in pancreatic beta cells prevents diabetes. $J$ Clin Invest 112, 1521-1532 (2003)

92. Fantin V. R., Q. Wang, G. E. Lienhard \& S. R. Keller: Mice lacking insulin receptor substrate 4 exhibit mild defects in growth, reproduction, and glucose homeostasis. Am J Physiol Endocrinol Metab 278, E127-133 (2000)

93. Liu S. C., Q. Wang, G. E. Lienhard \& S. R. Keller: Insulin receptor substrate 3 is not essential for growth or glucose homeostasis. J Biol Chem 274, 18093-18099 (1999)

94. Lavan B. E., V. R. Fantin, E. T. Chang, W. S. Lane, S. R. Keller \& G. E. Lienhard: A novel 160-kDa phosphotyrosine protein in insulin-treated embryonic kidney cells is a new member of the insulin receptor substrate family. J Biol Chem 272, 2140321407 (1997)

95. Lavan B. E., W. S. Lane \& G. E. Lienhard: The 60-kDa phosphotyrosine protein in insulin-treated adipocytes is a new member of the insulin receptor substrate family. J Biol Chem 272, 11439-11443 (1997)

96. Han S., C. P. Liang, T. Devries-Seimon, M. Ranalletta, C. L. Welch, K. Collins-Fletcher, D. Accili, I. Tabas \& A. R. Tall: Macrophage insulin receptor deficiency increases ER stress-induced apoptosis and necrotic core formation in advanced atherosclerotic lesions. Cell Metab 3, 257-266 (2006)

97. Griffin E., A. Re, N. Hamel, C. Fu, H. Bush, T. McCaffrey \& A. S. Asch: A link between diabetes and atherosclerosis: Glucose regulates expression of CD36 at the level of translation. Nat Med 7, 840-846 (2001)

98. Sampson M. J., I. R. Davies, S. Braschi, K. Ivory \& D. A. Hughes: Increased expression of a scavenger receptor (CD36) in monocytes from subjects with Type 2 diabetes. Atherosclerosis 167, 129-134 (2003)

99. Baumgartl J., S. Baudler, M. Scherner, V. Babaev, L. Makowski, J. Suttles, M. McDuffie, S. Fazio, C. R. Kahn, G. S. Hotamisligil, W. Krone, M. Linton \& J. C. Bruning: Myeloid lineage cell-restricted insulin resistance protects apolipoproteinEdeficient mice against atherosclerosis. Cell Metab 3, 247-256 (2006)

100. Gonzalez-Navarro H., M. Vila-Caballer, M. F. Pastor, A. Vinue, M. F. White, D. Burks \& V. Andres: Plasma insulin levels predict the development of atherosclerosis when IRS2 deficiency is combined with severe hypercholesterolemia in apolipoprotein E-null mice. Front Biosci 12, 2291-2298 (2007)

101. Clough M. H., D. J. Schneider, B. E. Sobel, M. F. White, M. P. Wadsworth \& D. J. Taatjes: Attenuation of accumulation of neointimal lipid by pioglitazone in mice genetically deficient in insulin receptor substrate-2 and apolipoprotein E. $J$ Histochem Cytochem 53, 603-610 (2005)

102. Van Belle E., C. Bauters, E. Hubert, J. C. Bodart, K. Abolmaali, T. Meurice, E. P. McFadden, J. M. Lablanche \& M. E. Bertrand: Restenosis rates in diabetic patients: a comparison of coronary stenting and balloon angioplasty in/native coronary vessels. Circulation 96, 1454-1460 (1997)

103. Mercado N., E. Boersma, W. Wijns, B. J. Gersh, C. A. Morillo, V. de Valk, G. A. van Es, D. E. Grobbee \& P. W. Serruys: Clinical and quantitative coronary angiographic predictors of coronary restenosis: a comparative analysis from the balloon-tostent era. J Am Coll Cardiol 38, 645-652 (2001)

104. Elezi S., A. Kastrati, J. Pache, A. Wehinger, M. Hadamitzky, J. Dirschinger, F. J. Neumann \& A. Schomig: Diabetes mellitus and the clinical and angiographic outcome after coronary stent placement. J Am Coll Cardiol 32, 1866-1873 (1998)

105. Schofer J., M. Schluter, T. Rau, F. Hammer, N. Haag \& D. G. Mathey: Influence of treatment modality on angiographic outcome after coronary stenting in diabetic patients: a controlled study. J Am Coll Cardiol 35, 1554-1559 (2000)

106. Van Belle E., M. Perie, D. Braune, A. Chmait, T. Meurice, K. Abolmaali, E. P. McFadden, C. Bauters, J. M. Lablanche \& M. E. Bertrand: Effects of coronary stenting on vessel patency and long-term clinical outcome after percutaneous coronary revascularization in diabetic patients. J Am Coll Cardiol 40, 410-417 (2002)

107. Kanzaki T., M. Shinomiya, S. Ueda, N. Morisaki, Y. Saito \& S. Yoshida: Enhanced arterial intimal thickening after balloon catheter injury in diabetic animals accompanied by PDGF beta-receptor overexpression of aortic media. Eur J Clin Invest 24 , 377-381 (1994)

108. Winocour P. D. \& L. Hryhorenko: Spontaneous diabetes in BB Wistar rats causes small increases in the early proliferative response of smooth muscle cells in re-injured aortae. Exp Mol Pathol 63, 161-174 (1995)

109. Stephenson K., J. Tunstead, A. Tsai, R. Gordon, S. Henderson \& H. M. Dansky: Neointimal formation after endovascular arterial injury is markedly attenuated in $\mathrm{db} / \mathrm{db}$ mice. Arterioscler Thromb Vasc Biol 23, 2027-2033 (2003)

110. Park S. H., S. P. Marso, Z. Zhou, F. Foroudi, E. J. Topol \& A. M. Lincoff: Neointimal hyperplasia after arterial injury is increased in a rat model of non-insulin-dependent diabetes mellitus. Circulation 104, 815-819 (2001)

111. Indolfi C., D. Torella, L. Cavuto, A. M. Davalli, C. Coppola, G. Esposito, M. V. Carriero, A. Rapacciuolo, E. Di Lorenzo, E. Stabile, C. Perrino, A. Chieffo, F. Pardo \& M. Chiariello: Effects of balloon injury on neointimal hyperplasia in streptozotocininduced diabetes and in hyperinsulinemic nondiabetic pancreatic islet-transplanted rats. Circulation 103, 2980-2986 (2001)

112. Haudenschild C. C., W. Van Sickle \& A. V. Chobanian: Response of the aorta of the obese Zucker rat to injury. Arteriosclerosis 1, 186-191 (1981)

113. Zhou Z., K. Wang, M. S. Penn, S. P. Marso, M. A. Lauer, F. Forudi, X. Zhou, W. Qu, Y. Lu, D. M. Stern, A. M. Schmidt, A. M. Lincoff \& E. J. Topol: Receptor for AGE (RAGE) mediates neointimal formation in response to arterial injury. Circulation $107,2238-2243(2003)$

114. Moroi M., L. Zhang, T. Yasuda, R. Virmani, H. K. Gold, M. C. Fishman \& P. L. Huang: Interaction of genetic deficiency of endothelial nitric oxide, gender, and pregnancy in vascular response to injury in mice. J Clin Invest 101, 1225-1232 (1998) 


\section{Murine models of diabetic atherosclerosis}

115. Kubota T., N. Kubota, M. Moroi, Y. Terauchi, T. Kobayashi, K. Kamata, R. Suzuki, K. Tobe, A. Namiki, S. Aizawa, R. Nagai, T. Kadowaki \& T. Yamaguchi: Lack of insulin receptor substrate-2 causes progressive neointima formation in response to vessel injury. Circulation 107, 3073-3080 (2003)

116. Foster E., S. Zhang \& A. M. Kahn: Insulin stimulates arterial neointima formation in normal rats after balloon injury. Diabetes Obes Metab 8, 348-351 (2006)

117. Yang M., E. Foster \& A. M. Kahn: Insulin-stimulated NAD(P)H oxidase activity increases migration of cultured vascular smooth muscle cells. Am J Hypertens 18, 1329-1334 (2005)

118. Naka Y., L. G. Bucciarelli, T. Wendt, L. K. Lee, L. L. Rong, R. Ramasamy, S. F. Yan \& A. M. Schmidt: RAGE axis: Animal models and novel insights into the vascular complications of diabetes. Arterioscler Thromb Vasc Biol 24, $1342-1349$ (2004)

119. Bucciarelli L. G., T. Wendt, W. Qu, Y. Lu, E. Lalla, L. L. Rong, M. T. Goova, B. Moser, T. Kislinger, D. C. Lee, Y. Kashyap, D. M. Stern \& A. M. Schmidt: RAGE blockade stabilizes established atherosclerosis in diabetic apolipoprotein E-null mice. Circulation 106, 2827-2835 (2002)

120. Forbes J. M., L. T. Yee, V. Thallas, M. Lassila, R. Candido, K. A. Jandeleit-Dahm, M. C. Thomas, W. C. Burns, E. K. Deemer, S. M. Thorpe, M. E. Cooper \& T. J. Allen: Advanced glycation end product interventions reduce diabetes-accelerated atherosclerosis. Diabetes 53, 1813-1823 (2004)

121. Lin R. Y., R. P. Choudhury, W. Cai, M. Lu, J. T. Fallon, E. A. Fisher \& H. Vlassara: Dietary glycotoxins promote diabetic atherosclerosis in apolipoprotein E-deficient mice. Atherosclerosis 168, 213-220 (2003)

122. Shoji T., H. Koyama, T. Morioka, S. Tanaka, A. Kizu, K. Motoyama, K. Mori, S. Fukumoto, A. Shioi, N. Shimogaito, M. Takeuchi, Y. Yamamoto, H. Yonekura, H. Yamamoto \& Y. Nishizawa: Receptor for advanced glycation end products is involved in impaired angiogenic response in diabetes. Diabetes 55, 2245-2255 (2006)

123. Candido R., K. A. Jandeleit-Dahm, Z. Cao, S. P. Nesteroff, W. C. Burns, S. M. Twigg, R. J. Dilley, M. E. Cooper \& T. J. Allen: Prevention of accelerated atherosclerosis by angiotensin-converting enzyme inhibition in diabetic apolipoprotein Edeficient mice. Circulation 106, 246-253 (2002)

124. Candido R., T. J. Allen, M. Lassila, Z. Cao, V. Thallas, M. E. Cooper \& K. A. Jandeleit-Dahm: Irbesartan but not amlodipine suppresses diabetes-associated atherosclerosis. Circulation 109, 1536-1542 (2004)

125. Jandeleit-Dahm K., M.Lassila, B. J. Davis, R. Candido, C. I. Johnston, T. J. Allen, L. M. Burrell \& M. E. Cooper: Antiatherosclerotic and renoprotective effects of combined angiotensin-converting enzyme and neutral endopeptidase inhibition in diabetic apolipoprotein E-knockout mice. J Hypertens 23, 2071-2082 (2005)

126. Shawver L. K., D. Slamon \& A. Ullrich. Smart drugs: tyrosine kinase inhibitors in cancer therapy. Cancer Cell 1, 117-123 (2002)

127. Myllarniemi M., J. Frosen, L. G. Calderon Ramirez, E. Buchdunger, K. Lemstrom \& P. Hayry: Selective tyrosine kinase inhibitor for the platelet-derived growth factor receptor in vitro inhibits smooth muscle cell proliferation after reinjury of arterial intima in vivo. Cardiovasc Drugs Ther 13, 159-168 (1999)

128. Boucher P., M. Gotthardt, W. P. Li, R. G. Anderson \& J. Herz: LRP: role in vascular wall integrity and protection from atherosclerosis. Science 300, 329-332 (2003)

129. Sihvola R. K., J. M. Tikkanen, R. Krebs, E. M. Aaltola, E. Buchdunger, O. Laitinen, P. K. Koskinen \& K. B. Lemstrom: Platelet-derived growth factor receptor inhibition reduces allograft arteriosclerosis of heart and aorta in cholesterol-fed rabbits. Transplantation 75, 334-339 (2003)

130. Lassila M., T. J. Allen, Z. Cao, V. Thallas, K. A. Jandeleit-Dahm, R. Candido \& M. E. Cooper: Imatinib attenuates diabetesassociated atherosclerosis. Arterioscler Thromb Vasc Biol 24, 935-942 (2004)

131. Mendelsohn M. E. \& R. H. Karas: The protective effects of estrogen on the cardiovascular system. N Engl J Med 340, 1801$1811(1999)$

132. Tse J., B. Martin-McNaulty, M. Halks-Miller, K. Kauser, V. DelVecchio, R. Vergona, M. E. Sullivan \& G. M. Rubanyi: Accelerated atherosclerosis and premature calcified cartilaginous metaplasia in the aorta of diabetic male Apo E knockout mice can be prevented by chronic treatment with 17 beta-estradiol. Atherosclerosis 144, 303-313 (1999)

133. Hermanowski-Vosatka A., J. M. Balkovec, K. Cheng, H. Y. Chen, M. Hernandez, G. C. Koo, C. B. Le Grand, Z. Li, J. M. Metzger, S. S. Mundt, H. Noonan, C. N. Nunes, S. H. Olson, B. Pikounis, N. Ren, N. Robertson, J. M. Schaeffer, K. Shah, M. S. Springer, A. M. Strack, M. Strowski, K. Wu, T. Wu, J. Xiao, B. B. Zhang, S. D. Wright \& R. Thieringer: 11 beta-HSD1 inhibition ameliorates metabolic syndrome and prevents progression of atherosclerosis in mice. J Exp Med 202, 517-527 (2005)

134. Worth N. F., C. L. Berry, A. C. Thomas \& J. H. Campbell: S18886, a selective TP receptor antagonist, inhibits development of atherosclerosis in rabbits. Atherosclerosis 183, 65-73 (2005)

135. Cayatte A. J., Y. Du, J. Oliver-Krasinski, G. Lavielle, T. J. Verbeuren \& R. A. Cohen: The thromboxane receptor antagonis S18886 but not aspirin inhibits atherogenesis in apo E-deficient mice: evidence that eicosanoids other than thromboxane contribute to atherosclerosis. Arterioscler Thromb Vasc Biol 20, 1724-1728 (2000)

136. Zuccollo A., C. Shi, R. Mastroianni, K. A. Maitland-Toolan, R. M. Weisbrod, M. Zang, S. Xu, B. Jiang, J. M. OliverKrasinski, A. J. Cayatte, S. Corda, G. Lavielle, T. J. Verbeuren \& R. A. Cohen: The thromboxane A2 receptor antagonist S18886 prevents enhanced atherogenesis caused by diabetes mellitus. Circulation 112, 3001-3008 (2005)

137. Lefebvre P., G. Chinetti, J. C. Fruchart \& B. Staels: Sorting out the roles of PPAR alpha in energy metabolism and vascular homeostasis. J Clin Invest 116, 571-580 (2006)

138. Staels B., J. Dallongeville, J. Auwerx, K. Schoonjans, E. Leitersdorf \& J. C. Fruchart: Mechanism of action of fibrates on lipid and lipoprotein metabolism. Circulation 98, 2088-2093 (1998) 


\section{Murine models of diabetic atherosclerosis}

139. Calkin A. C., M. E. Cooper, K. A. Jandeleit-Dahm \& T. J. Allen: Gemfibrozil decreases atherosclerosis in experimental diabetes in association with a reduction in oxidative stress and inflammation. Diabetologia 49, 766-774 (2006)

140. Calkin A. C., J. M. Forbes, C. M. Smith, M. Lassila, M. E. Cooper, K. A. Jandeleit-Dahm \& T. J. Allen: Rosiglitazone attenuates atherosclerosis in a model of insulin insufficiency independent of its metabolic effects. Arterioscler Thromb Vasc Biol 25, 1903-1909 (2005)

141. Calkin A. C., S. Giunti, K. A. Jandeleit-Dahm, T. J. Allen, M. E. Cooper \& M. C. Thomas: PPAR-\{alpha $\}$ and -\{gamma $\}$ agonists attenuate diabetic kidney disease in the apolipoprotein E knockout mouse. Nephrol Dial Transplant 21, 2399-2405 (2006)

142. Zadelaar A. S., L. S. Boesten, J. W. Jukema, B. J. van Vlijmen, T. Kooistra, J. J. Emeis, E. Lundholm, G. Camejo \& L. M. Havekes: Dual PPARalpha/gamma agonist tesaglitazar reduces atherosclerosis in insulin-resistant and hypercholesterolemic ApoE*3Leiden mice. Arterioscler Thromb Vasc Biol 26, 2560-2566 (2006)

143. Kaliora A. C., G. V. Dedoussis \& H. Schmidt: Dietary antioxidants in preventing atherogenesis. Atherosclerosis 187, 1-17 (2006)

144. Zang M., S. Xu, K. A. Maitland-Toolan, A. Zuccollo, X. Hou, B. Jiang, M. Wierzbicki, T. J. Verbeuren \& R. A. Cohen: Polyphenols Stimulate AMP-Activated Protein Kinase, Lower Lipids, and Inhibit Accelerated Atherosclerosis in Diabetic LDL Receptor-Deficient Mice. Diabetes 55, 2180-2191 (2006)

145. Yi X. \& N. Maeda: \{alpha\}-Lipoic Acid Prevents the Increase in Atherosclerosis Induced by Diabetes in Apolipoprotein EDeficient Mice Fed High-Fat/Low-Cholesterol Diet. Diabetes 55, 2238-2244 (2006)

146. Mackness B., R. Quarck, W. Verreth, M. Mackness \& P. Holvoet: Human paraoxonase-1 overexpression inhibits atherosclerosis in a mouse model of metabolic syndrome. Arterioscler Thromb Vasc Biol 26, 1545-1550 (2006)

Key Words: Atherosclerosis, Restenosis, Diabetes Mellitus, Irs, Metabolic Syndrome, Genetically-Modified Mice, Insulin Resistance, Chronic Inflammation, Hypercholesterolemia, Review

Send correspondence to: Vicente Andrés, PhD, Laboratory of Vascular Biology, Department of Molecular and Cellular Pathology and Therapy, Instituto de Biomedicina de Valencia (IBV-CSIC), Jaime Roig, 11, 46010 Valencia, Spain, Tel.: $34-$ 963391752, Fax: 34-963391751, E-mail: vandres@ibv.csic.es
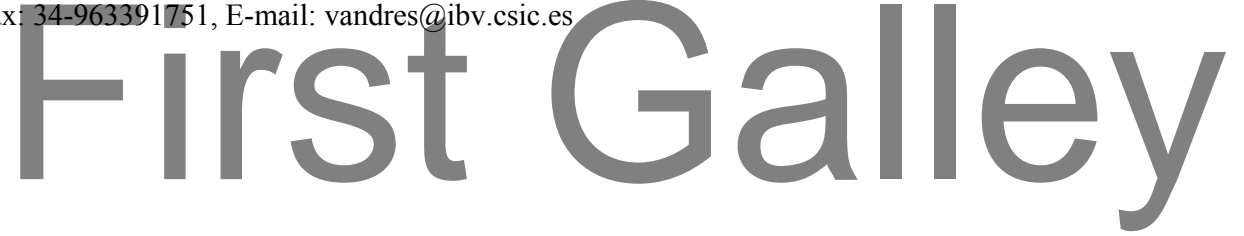


\section{Murine models of diabetic atherosclerosis}

Table 1. Proatherogenic plasma lipid alterations in diabetic patients

\begin{tabular}{|l|l|l|}
\hline Alteration & Mechanisms & Effects \\
\hline Hypertriglyceridemia & Increased plasma FFA level caused by augmented release from adipose tissue & Enhanced hepatic production of TG-rich VLDLs \\
\hline Increased plasma sdLDL & Stimulation of lipase activity on TG-rich lipoproteins & $\begin{array}{l}\text { Increased foam cell formation caused by augmented } \\
\text { accumulation of oxLDL within the subendothelial } \\
\text { space }\end{array}$ \\
\hline Decreased plasma HDL & Stimulation of lipase activity on TG-rich HDL & $\begin{array}{l}\text { Increased foam cell formation caused by decreased } \\
\text { reverse cholesterol transport }\end{array}$ \\
\hline
\end{tabular}

Table 2. Major proatherogenic vascular alterations in diabetic patients

\begin{tabular}{|l|l|}
\hline Alteration & Mechanism \\
\hline \multirow{3}{*}{ Increased plaque instability } & $\begin{array}{l}\text { Decreased neointimal collagen content caused by increased metalloproteinase expression/activity, and increased endothelial } \\
\text { production of cytokines that decreased VSMC-dependent collagen synthesis }\end{array}$ \\
\cline { 2 - 2 } & Glycated oxLDL-dependent VSMC apoptosis leading to reduced neointimal VSMC content \\
\hline Increased oxidative stress & Decreased production of endothelial NO \\
\cline { 2 - 2 } & Increased production of reactive oxygen species in ECs and VSMCs \\
\cline { 2 - 2 } & Activation of platelets \\
\cline { 2 - 2 } & Impaired fibrinolysis \\
\hline
\end{tabular}

Table 3. Atherosclerosis in mouse models of diabetes and insulin resistance

\begin{tabular}{|c|c|c|c|c|c|}
\hline $\begin{array}{l}\text { Diabetic } \\
\text { phenotype }\end{array}$ & Mouse model & Diabetic agent & Atherogenic agent & Effect on atherosclerosis & Ref. \\
\hline \multirow{7}{*}{$\begin{array}{l}\text { Type 1- } \\
\text { DM }\end{array}$} & $\mathrm{BALB} / \mathrm{c}$ & STZ & Hyperlipidemia (high-fat feeding) & Increased & 36 \\
\hline & apoE-KO & STZ & Hyperlipidemia (apoE disruption) & Increased & 39 \\
\hline & LDLR-KO & STZ & $\begin{array}{l}\text { Hyperlipidemia (LDLR disruption } \\
\text { and high-fat feeding) }\end{array}$ & $\begin{array}{l}\text { No change } \\
\text { (mice treated with low-dose insulin) }\end{array}$ & 42 \\
\hline & LDLR-KO & STZ & $\begin{array}{l}\text { Hyperlipidemia (LDLR disruption } \\
\text { and high-fat feeding) }\end{array}$ & Increased & 43 \\
\hline & $\begin{array}{l}\text { apoB/LPL1 } \\
\text { transgenic }\end{array}$ & STZ & $\begin{array}{l}\text { Hyperlipidemia (apoB } \\
\text { overexpression and high-fat feeding) }\end{array}$ & Increased & 45 \\
\hline & $\begin{array}{l}\text { GP transgenic: } \\
\text { LDLR-KO }\end{array}$ & $\begin{array}{l}\text { Autoimmune destruction of } \beta \text { - } \\
\text { cells }\end{array}$ & $\begin{array}{l}\text { Hyperlipidemia (LDLR disruption } \\
\text { and high-fat feeding) }\end{array}$ & Increased & 47 \\
\hline & NOD & $\begin{array}{l}\text { Autoimmune destruction of } \beta \text { - } \\
\text { cells }\end{array}$ & Hyperlipidemia (high-fat feeding) & & 51 \\
\hline \multirow{9}{*}{ Type 2-DM } & $\begin{array}{l}\text { Lipocalin-type } \\
\text { prostaglandin D(2) } \\
\text { synthase (L-PGDS)- } \\
\text { KO }\end{array}$ & $\begin{array}{l}\text { L-PGDS disruption combined } \\
\text { with diabetogenic diet leading } \\
\text { to reduced insulin sensitivity } \\
\text { and glucose transport }\end{array}$ & Hyperlipidemia & $\begin{array}{l}\text { Aortic thickening reminiscent to the } \\
\text { early stages of atherosclerosis }\end{array}$ & 61 \\
\hline & apoE-KO & $\begin{array}{l}\text { Gold thioglucose (destruction } \\
\text { of leptin-receptor positive } \\
\text { neurons) }\end{array}$ & Hyperlipidemia (apoE disruption) & Decreased & 63 \\
\hline & Lep $^{\mathrm{ob} / \mathrm{ob}}:$ LDLR-KO & Absence of leptin function & Hyperlipidemia (LDLR disruption) & Increased & 70,73 \\
\hline & Lepr $^{\mathrm{db} / \mathrm{db}}:$ apoE-KO & Absence of leptin function & $\begin{array}{l}\text { Hyperlipidemia (apoE disruption } \\
\text { with or without high-fat feeding) }\end{array}$ & Increased & $73-75$ \\
\hline & $\begin{array}{l}\text { LDLR-KO } \\
\text { transplanted with } \\
\text { INSR-null bone } \\
\text { marrow } \\
\end{array}$ & $\begin{array}{l}\text { Impaired insulin signaling in } \\
\text { macrophages (macrophage- } \\
\text { specific INSR disruption) }\end{array}$ & $\begin{array}{l}\text { Hyperlipidemia (LDLR disruption } \\
\text { and high-fat feeding) }\end{array}$ & Increased & 96 \\
\hline & $\begin{array}{l}\text { apoE-KO } \\
\text { transplanted with } \\
\text { INSR-null bone } \\
\text { marrow } \\
\end{array}$ & $\begin{array}{l}\text { Impaired insulin signaling in } \\
\text { macrophages (macrophage- } \\
\text { specific INSR disruption) }\end{array}$ & $\begin{array}{l}\text { Hyperlipidemia (apoE disruption and } \\
\text { high-fat feeding) }\end{array}$ & Decreased & 99 \\
\hline & $\begin{array}{l}\text { apoE-KO } \\
\text { transplanted with } \\
\text { IRS-2-null fetal liver } \\
\text { cells marrow } \\
\end{array}$ & $\begin{array}{l}\text { Impaired insulin signaling in } \\
\text { myeloid cells (myeloid lineage } \\
\text { cell-restricted IRS-2 } \\
\text { disruption) }\end{array}$ & $\begin{array}{l}\text { Hyperlipidemia (apoE disruption and } \\
\text { high-fat feeding) }\end{array}$ & Decreased & 99 \\
\hline & apoE-KO:IRS-2-KO & $\begin{array}{l}\text { Impaired insulin signaling } \\
\text { (global IRS-2 disruption) }\end{array}$ & $\begin{array}{l}\text { Hyperlipidemia (apoE disruption and } \\
\text { high-fat feeding) }\end{array}$ & Increased & 99,100 \\
\hline & apoE-KO:IRS-2+/- & $\begin{array}{l}\text { Impaired insulin signaling } \\
\text { (global disruption of one allele } \\
\text { of IRS-2) }\end{array}$ & $\begin{array}{l}\text { Hyperlipidemia (apoE disruption and } \\
\text { high-fat feeding) }\end{array}$ & Increased & 101 \\
\hline
\end{tabular}

Table 4. Animal models to study the effects of altered leptin/glucose/insulin signaling on neointimal thickening induced by mechanical injury

\begin{tabular}{|l|l|l|l|l|}
\hline Alteration & Animal model & Type of injury and effect on neointimal & Lesion size & Ref. \\
\hline \multirow{5}{*}{ Type 1-DM } & STZ-treated Sprague Dawley rat & Balloon angioplasty of carotid artery & No change & 110 \\
\cline { 2 - 5 } & STZ-treated Wistar rat & Balloon angioplasty of carotid artery & Decreased \\
\cline { 2 - 5 } & ins2 ${ }^{\text {Akita }}$ mouse & Wire denudation of femoral artery & No change & 111 \\
\cline { 2 - 5 } & Alloxan-treated rabbit & Balloon angioplasty of carotid artery & Increased & 109 \\
\cline { 2 - 5 } & BB Wistar rat & Balloon angioplasty of aorta & Increased & 108 \\
\hline \multirow{5}{*}{ Type 2-DM } & Lepr ${ }^{\mathrm{db} / \mathrm{db}}$ mouse & Wire denudation of femoral artery & Decreased & 109 \\
\cline { 2 - 5 } & & Balloon angioplasty of carotid artery & Increased & 110 \\
\cline { 2 - 6 } & Obese Zucker rat (mutated leptin receptor; Type 2 DM) & Balloon angioplasty of thoracic aorta & Increased & 112 \\
\end{tabular}




\section{Murine models of diabetic atherosclerosis}

\begin{tabular}{|l|l|l|l|l|}
\hline & & Balloon angioplasty of carotid artery & No change & 113 \\
\cline { 2 - 5 } & IRS-2-KO mouse & Cuff placement in femoral artery & Increased & 115 \\
\hline Insulin resistance & IRS-1-KO mouse & Cuff placement in femoral artery & No change & 115 \\
\hline \multirow{3}{*}{ Hyperinsulinemia } & STZ-treated Wistar rat infused with insulin & Balloon angioplasty of carotid artery & Increased & 111 \\
\cline { 2 - 5 } & Sprague-Dawley rat infused with insulin & Balloon angioplasty of carotid artery & Increased & 116 \\
\cline { 2 - 5 } & Fisher rat transplanted with pancreatic islets & Balloon angioplasty of carotid artery & Increased & 111 \\
\hline
\end{tabular}

Table 5. Therapies for treating accelerated diabetic atherosclerosis in the mouse

\begin{tabular}{|c|c|c|c|}
\hline Mouse model & Treatment & Effects & Ref. \\
\hline $\begin{array}{l}\text { STZ-treated apoE-KO } \\
\text { and } \\
\text { Lepr }^{\mathrm{db} / \mathrm{db}}: \text { apoE-KO }\end{array}$ & $\begin{array}{l}\text { Soluble extracellular ligand-binding domain of } \\
\text { RAGE (sRAGE) }\end{array}$ & $\begin{array}{l}\text { Reduction of atherosclerosis in a glycemia- and lipid- } \\
\text { independent manner (also in nondiabetic Lepr }{ }^{\mathrm{m} / \mathrm{db}} ; \text { apoE-KO } \\
\text { controls). Stabilization of established atheromas }\end{array}$ & $39,75,119$ \\
\hline STZ-treated apoE-KO & $\begin{array}{l}\text { ALT-711 (AGE cross-linker breaker) } \\
\text { Aminoguanidine (Age formation inhibitor) }\end{array}$ & $\begin{array}{l}\text { Reduction of vascular AGE accumulation and atherosclerotio } \\
\text { plaque area and complexity }\end{array}$ & 120 \\
\hline STZ-treated apoE-KO & 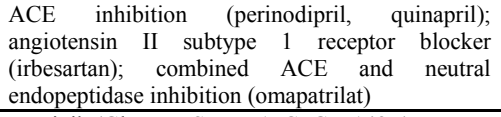 & Reduction of atherosclerosis & $123-125$ \\
\hline STZ-treated apoE-KO & Imatinib (Gleevec, STI-571, CPG57148B) & Reduction of atherosclerosis & 130 \\
\hline STZ-treated apoE-KO & $17 \beta$-estradiol & $\begin{array}{l}\text { Reduction of plasma glucose and TG levels and prevention } \\
\text { of atherosclerosis and premature calcified cartilaginous } \\
\text { metplasia in the aorta }\end{array}$ & 132 \\
\hline STZ-treated apoE-KO & S18886 (thromboxane A2 receptor antagonist) & $\begin{array}{l}\text { Reduction of atherosclerosis in a glycemia- and lipid- } \\
\text { independent manner }\end{array}$ & 136 \\
\hline Lepr $^{\mathrm{db} / \mathrm{db}}:$ apoE-KO & Fenofibrate (PPAR- $\alpha$ agonist) & $\begin{array}{l}\text { Diminished diet-induced atherosclerosis accompanied by } \\
\text { only } 30 \% \text { reduction of total plasma cholesterol }\end{array}$ & 74 \\
\hline STZ-treated apoE-KO & $\begin{array}{l}\text { Gemfibrozil (PPAR- } \alpha \text { agonist) } \\
\text { Rosiglitazone (PPAR- } \gamma \text { agonist) }\end{array}$ & $\begin{array}{l}\text { Reduction of atherosclerosis in a glycemia- and lipid- } \\
\text { independent manner }\end{array}$ & 139,140 \\
\hline STZ-treated LDLR-KO & S17834 (polyphenol) & $\begin{array}{lllll}\begin{array}{l}\text { Inhibition of hyperlipidemia } \\
\text { atherosclerosis }\end{array} & \text { and reduced aortic } \\
\end{array}$ & 144 \\
\hline apoE*3Leiden & Tesaglitazar (dual PPAR- $\alpha / \gamma$ agonist) & $\begin{array}{l}\text { Inhibition of hyperlipidemia and reduced aortic } \\
\text { atherosclerosis (beyond plasma cholesterol lowering) }\end{array}$ & 142 \\
\hline STZ-treated apoE-KO & $\alpha$-lipoic acid (natural antioxidant) & $\begin{array}{l}\text { Lowering of markers of oxidative stress, plasma glucose and } \\
\text { cholesterol levels, and reduction of atherosclerosis }\end{array}$ & 145 \\
\hline Lep $^{\text {ob/ob }}:$ LDLR-KO & $\begin{array}{l}\text { Adenovirus-mediated overexpression of PON1 } \\
\text { (antioxidant enzyme that prevents LDL oxidation) }\end{array}$ & $\begin{array}{l}\text { Reduced atherosclerosis without ameliorating dyslipidemia } \\
\text { Reduced macrophage and oxLDL content and increased } \\
\text { VSMC content in atherosclerotic plaques }\end{array}$ & 146 \\
\hline
\end{tabular}


Murine models of diabetic atherosclerosis
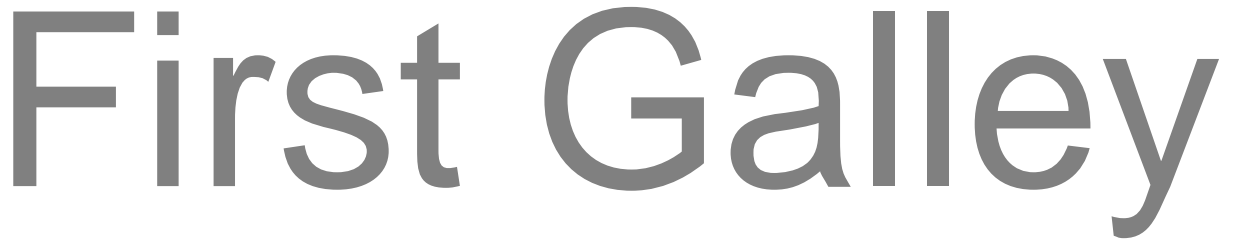